\title{
Seeing thought: a cultural cognitive tool
}

\author{
José Morais • Régine Kolinsky
}

Received: 15 September 2019/Revised: 1 June 2020/Accepted: 3 June 2020/Published online: 9 June 2020

(C) The Author(s) 2020

\begin{abstract}
The present paper, which is the first of two twin opinion papers, offers a theoretical approach of literacy and critical literacy in relation to language, thought, and reasoning. Literacy acquisition and practice proceed through two stages, which partially overlap in terms of processing abilities: the first is achieved when the learner becomes a skilled reader and writer, characterized by automatic word processing; the second, when reading comprehension and written production become expert instruments in the communication of progressively more abstract and sophisticated, but always linguistically-mediated, knowledge and ideas. The destiny of literacy, depending on educational and social factors, is thus to be to fused with language, thought and reasoning. Oral language becomes literate language; and our cognitive activity becomes - as indicated in the title- "seeing thought", which paves the way, we will argue, for reasoning skills. Making of literacy an epistemic and social tool of our own collective history requires a
\end{abstract}

J. Morais · R. Kolinsky ( $\square)$

Unité de Recherche en Neurosciences Cognitives

(Unescog), Center for Research in Cognition and

Neurosciences (CRCN), Université Libre de Bruxelles

(ULB), 50 Av. F. Roosevelt. CP 191, 1050 Brussels,

Belgium

e-mail: rkolins@ulb.ac.be

R. Kolinsky

Fonds de La Recherche Scientifique-FNRS (FRS-FNRS),

Brussels, Belgium critical stance that raises itself and ourselves to a stage called critical literacy. In this paper we focus on some of the favorable and unfavorable factors influencing this achievement. The main challenge is to bring literate cognition up to the capacity of choosing between accept and verify, between belief and disbelief, by weighting evidence and reasoning, by arguing and debunking errors and falsities. Accordingly, our objective is essentially to narrate how literacy gives birth to critical literacy and explain why, at the end of this process, critical literacy becomes hard to distinguish from thinking and reasoning.

Keywords Literacy · Critical literacy · Thinking · Reasoning · Argumentation

\section{Introduction}

The present paper is the first of two twin opinion papers on literacy. Literacy designates capacities and/ or domains: "philosophical/scientific/literary literacies", "creative/critical literacies", "poor/rich literacies". The adjective literate qualifies either people, mental processes, events, systems and/or modes of intervention: "literate person/society", "literate thinking/reasoning", "literate revolution/culture/education". In both papers, we refer to alphabetic scripts exclusively. First, because unfortunately we do not 
know enough about the other writing systems; second, because it is in reference to alphabetic scripts that most of the important theoretical issues were raised and dealt with in the cognitive scientific literature. Even if, presumably, they are partly generalizable to other writing systems, we are aware that this is a consequence of the alphabetic imperialism due to the European historical power, later extended to all the West.

Literacy was the child of a couple, thinking and language. Together, they gave birth to reasoning. Reasoning is thinking fertilized by literacy. Thus, from the incestuous relationship of reasoning with literacy, did emerge, in particular, critical literacy. How this happened is a main topic of the first part of the present paper: From literacy to critical literacy narrates how literacy gave birth to critical literacy and explains in what ways the latter differs from her mother. Under the subtitle Literacy, we examine what is literacy and discuss why, in our view, it is much more than reading and writing abilities. We also examine how, historically, literacy and democracy entertained a reciprocal interaction, and argue that writing has a mightier impact than reading. Under the subtitle Critical literacy, we examine why this capacity is confined to elites, when and how it developed, why science is one of its forms, and why it requires free thinking.

In the second part of the present paper, From thinking to reasoning, we begin by proposing that thinking preceded language and is not exclusive to humans, and that reasoning, as presently conceptualized, has developed under the influence of literacy in the individual and/or in society, which explains why illiterates living in a literate society may be capable of reasoning. Next, we argue that both thinking and reasoning may support a critical purpose, which, with the emergence of literacy, led to what now is broadly called critical literacy-with many versions-and discuss epistemic verification as a basic cognitive component of critical literacy. Then, we examine the present literacy levels and claim that it is not possible to establish a rational literate world when it is made of a majority consisting of illiterates, poor literates, and uncritical literates. To close, we propose that critical literacy and argumentation can be taught to all people provided some political and social conditions are established and secured.

\section{From literacy to critical literacy}

Critical literacy is a particular kind of literacy and hence we will begin by considering the most current concepts of literacy and our own one before addressing the various concepts of critical literacy.

\section{Literacy}

\section{How to define literacy?}

The word literacy, which only appeared near the end of the nineteenth century, has been attributed rather different meanings. For the vast majority of literate people, literacy designates the ability to read and write. We have argued against this trivial conception. In Kolinsky and Morais (2018, p. 322), we defined literacy as "all that, in the individual or in the culture to which the individual belongs, results, has resulted, or will result directly or indirectly from the development and use of the writing technology". Indeed, although the trivial definition of literacy seems simple and clear, it is just superficial. Even if it were correct to define it as the ability to read and write, how accurately, rapidly, and productively should one read and write a text, and how long and how difficult should that text be, to be conferred those abilities?

The United Nations (UN) organization officialized the most liberal criterion of reading and writing ability one might imagine: a brief and simple text of the person's daily life (UNESCO, United Nations Educational, Scientific and Cultural Organization 1997). Given the enormous differences between the daily lives of the contemporaneous human beings, we bet that at least two thirds of the world adult population would be unable both to read with comprehension anyone of the UN's reports and write on it an understandable comment. Besides, in the scientific papers dealing with reading and writing acquisition, there is usually no indication of a criterion distinguishing people who could be considered as literate from those who would not. It is indeed difficult to specify boundaries between stages in the course of the long-term acquisition process of reading and writing words and text.

In the case of alphabetic writing, there is an important temporal overlap, and mutual influence, between understanding the alphabetic principle and acquiring knowledge of the grapheme-phoneme and 
phoneme-grapheme relations, either isolated or in a syllabic context; between this acquisition and word reading and spelling; and, finally, between automatic word recognition and production, including in sentence context. There is indeed a concatenation of reciprocal influences across levels of processing: sublexical, lexical and sentential. Such influences also account for the fact that we, adults or children, read much more fluently words than pseudowords (Forster and Chambers 1973; Schwanenflugel et al. 2006) and more words presented in sentences than randomly (Biemiller 1977-1978; Stanovich 1980).

Beyond the close relationships in the acquisition of those "technological" components of reading and writing, there are also constant mutual influences between such acquisitions and the cognitive components involved in comprehension and production. One learns a technique while using it, in this case in and along the practice of both understanding the meaning of written language and transcribing spoken or mentally produced language. One outstanding case of the contribution of a low-level reading skill to the establishment of a higher order reading process is the passage of fast and successful but still sequential word decoding to single-fixation word identification, demonstrated and theorized by Share $(1995,1999)$ as resulting from a "self-teaching" mechanism. At an upper level, another worth mentioning case of skill extrapolation is the increasing use of subordinate clauses and recursion in literates' spoken language as a consequence of the frequent and interactive encounters with such structures in text reading and writing (e.g., Dabrowska 1997).

There is a further phenomenon that is neglected in almost all of the scientific literature on literacy acquisition: It is the fact that the practice of literacy feedbacks on most if not all of our cognitive capacities. In particular, beyond some aspects of visual and auditory perception, it feedbacks on memory, attention, chunking and structuring knowledge, imaging, prospecting, thinking and reasoning (as argued by Kolinsky and Morais 2018), and, beyond cognition, probably also on creativity, emotions, values, and personality.

Given this quite complex dynamic, how can we categorize people as literate or non-literate? Even people who are illiterate according to the UN definition are not completely naïve as regards literacy if they live in a literate society: They assimilate some literacy concepts from literate people with whom they interact. This implies that illiterates in our time have, in all likelihood, developed capacities sensible to literacy that illiterates in illiterate societies could not. As a consequence, comparing today literates and illiterates only provides an underestimation of the effects of literacy.

Obviously, we need to have a more precise idea of the literacy state of humanity and of each population than the one afforded by the UN's definition. Yet, let us admit, for a while, the quite common reductionist definition of literacy as the ability to read and write. If so, we should consider that literates are those who, whatever the writing system, are able to read and write words in an automatic way, and this is the criterion we use below when using this term. This presupposes that literates do much more than translating spoken into written language and vice-versa, as one cannot be an automatic reader and speller without being also able to understand, communicate, think and reason in some form of language, signed or spoken. Somebody said an illiterate is not equal to a literate minus the mastery of the written language. This claim expresses perfectly the fact that literacy is much more than just reading and writing, how excellent these could be.

Literacy is not just reading and writing because our literate activities have important effects on us. Thus, literacy must include every capacity and every knowledge one develops, directly or indirectly, though reading and writing. By using these abilities, a cognitively poor human being becomes a richer one, in terms of capacity to understand - and to changeboth the world and her/himself. Neither UN nor any state does estimate the proportion of literates this way. If they had, they would probably have found that no country counts more literate than non-literate people. You, who are now reading this paper, are presumably literate whatever your opinion about it, but you are part of a minority (see Morais 2018). The claim that we live in a literate society is a lie or at least an unchecked belief.

The existence of a huge proportion of non-literates in our society, despite its extraordinary scientific and technological development and enough knowledge and means to educate practically everybody till the status of literate, testifies of its main characteristicinegalitarian, prioritizing an elite and its enrichment and material progress. The creation of such an elite led to the emergence of an image of the human beings that 
does not take into account the enormous disparities between them: the image of the highly educated literate, or of a presumed (and hence misleading) average portrait of literate individuals. This is the prototype of a society fragmented into individuals, and it is this prototype that is studied and described by contemporary human sciences. These have tended to develop in almost complete isolation. It has been the case of cognitive psychology as regards, for example, anthropology, history, sociology and political science. Cognitive psychology made strong links with neuroscience and artificial intelligence, which was a great advance, however unfortunately forgetting it is also a cultural science.

\section{Obliterating literacy}

To illustrate how much literacy has been obliterated, it is worth considering the "mind", an entity described and explained in many philosophical and scientific books. Our "mind" is literate, but literacy is usually not considered as an essential contributor to it. Yet the "mind" is an abstract concept that would not have been generated and settled if literacy had not been developed as it did. It is, indeed, literacy that allowed fixing mental processes as "mind" or "mental system" somewhere "in" the brain and gave "permanence to what is just permanent change" (Kolinsky and Morais 2018, p. 322).

The reified "mind" is nothing more than a conceptual abstraction, but mental processes do have material effects. Indeed, these processes are at the origin of books which can be venerated by deeply changing thinking, culture and society, or be trampled, if not burned, to avoid contagion. Regrettably, the mental processes described in cognitive psychology are those of an abstract individual, a sort of presumed average of literate individuals, and actually, in a more restrictive way, the cognitive portrait of the literate typical of the intellectual elite. This cognitive individualist bias (the mental activity of a brain as if it were isolated from society and from the social identity and ideology of its owner) reflects the unconscious sociopolitical ideology of the academician, the elitist prejudice of which (s)he is unaware. Studying cognition regardless of its social roots and context, the cognitivists tend to interpret their findings as reflecting universal human characteristics.
Presently, most of the research accomplished on "intelligence" also reflects this elitist prejudice, and the one on "mind" treats this as being at the same time unique and representative of the species. Both of them are due to the individualist (conscious or not) perspective of the person who refuses to admit that any perspective is constrained by her/his socio-political dimension which is impossible to strip from her/ his mental processing. Importantly, the socio-political dimension of an individual does not reflect only her/ his material situation, it includes how each person lives mentally her/his role in the society.

As illustrated by Journals' names, in about one century and a half the discipline studying the mind changed its own name from "experimental psychology" to "experimental cognitive psychology", "cognitive psychology", "cognitive science", and in a collateral line, from "neuropsychology" to "cognitive neuropsychology", "cognitive neuroscience", and neuroscience tout court. All these mutations, during which there was some dialogue with philosophy (e.g., discussing if our mind is made of either modules or connected interactive networks), occurred for a long time in relative isolation from other human sciences, as we already commented on, and in particular from social sciences and historical sciences, including ethnology and anthropology. The late emergence and development of social psychology and social cognition did not approximate both sides as it could, and the historical sciences were until very recently object of distrust and even mockery (such as in some reactions to ethnologist studies, as those of Goody 1977).

Cognitive psychology, using experimental methods, considered itself_rightly_as science. Happy of linking mind to brain matter and activity, which in itself was a huge advance, it espoused to a large extent the reductionist bias and thus made a grave mistake: It neglected the social and cultural determinants of cognition. The creation of intelligent machines paved the way for a non-human cognitive science that is offering an exciting model for the human mind, eagerly accepted. Now, more exactly since the beginning of the 21th century, the human cognitive science risks to fall, more exactly is falling, in the arms of a new form of capitalist system.

Across history, the link between science and the economic system is assured by technology. Nowadays, there is an intimate three-way interaction between (1) cognitive science, (2) computerized 
processing and learning, and (3) exploitation by private companies of these resources and data, to identify, monitor and influence purchasing and consuming behaviours, and to keep in power pro-capitalism politicians. Zuboff (2019) calls this surveillance capitalism (henceforth, SC). It combines with traditional forms of capitalism: industrial, commercial and financial. She described how this process goes well beyond cognitive science and changes human sociability, motivation, affect, emotion and values. More exactly, this new process-and project-is one of dehumanization: the creation of a society of domesticated human beings who obey the masked informational whip operated by a new form of supreme elite: "business-scientists", who, while treating mind as computer and computer as mind, reign over both a court of extremely or just comfortably rich squires and the vast low class.

Forget literacy. Forget it has a tremendous influence on human cognition to the point of creating a cognitive machine superior in some regards to our own cognition. Forget that billions of people are nonliterate, forget that most of these could, but do not, share the same kind of mind as ours. This is what we are implicitly told. More generally, forget that this unequal and unethical situation is becoming dramatic, stimulated by the combination of IS (implementation science) and SS (surveillance systems) under the affectionate protection of SC (surveillance capitalism, Zuboff 2019), and be sure that the RIPs-Rich, Intelligent and Powerful-will succeed in installing definitely their private $W E B$ (Work for us, open Ears to us, $B$ uy for us). If we forget all that and have a withered concept of literacy, then we live in a world that is not ours.

It is a fact that literacy blinded us, literate people, for many of the most crucial aspects of our existence and of our mental life. In principle, literacy is a great accomplishment: According to Goody and Watt (1963), literacy allowed replacing myth by history, opinion by truth, and acceptance by skepticism. Skepticism, and by implication epistemic verification, is essential for critical literacy. We believe it urgent critical literacy to take literacy itself as its main target. We, cognitive scientists, need to read our science with new eyes. There is no mind, neither quantities of minds, there are people each with a history of mental processes. While part of them are literate, the majority are non-literate. In this paper, we will take a different perspective on the mind issue, addressing cognition in terms of processing, but also in its social and cultural dimensions.

\section{The impact of literacy}

Literacy has been shown to impact the way we conceptualize speech, as well as speech perception, linguistic and nonlinguistic visual perception, verbal memory, sentence comprehension and production, as well as more transformative, higher-level cognitive capacities such as abstract thinking. Here we mention succinctly several empirical facts and their sources (for reviews, see Dehaene et al. 2015; Demoulin and Kolinsky 2016; Huettig and Mishra 2014; Kolinsky 2015).

For non-linguistic visual perception, literacy allows both enantiomorphy (e.g., Kolinsky et al. 2011) and better (Pegado et al. 2014) and more flexible (Ventura et al. 2013) visual analysis. For speech perception, it was found that the direction of reading influences listening (Bertelson 1972) and that orthographically consistent spoken words (but not pseudo-words) are perceived faster and more accurately than inconsistent ones (Ziegler and Ferrand 1998). Literacy has repeatedly been shown to strongly impact deliberate attention to speech units (namely phonemes, Morais et al. 1979), and also, to a lesser extent, non-deliberate attention (Morais et al. 1987). For auditory verbal memory, there are clear effects of literacy, especially for pseudowords (Castro-Caldas et al. 1988; Reis et al. 2003; Kosmidis et al. 2011). For lexical and semantic knowledge, there are many observations of a strong literacy effect (e.g., Kolinsky et al. 2014). Awareness of the word unit and its function also appears to be a consequence of literacy, most probably because words are separated in modern writing, not in speech (Kolinsky et al. 1987; Cary 1988; Ramachandra and Karanth 2007).

The degree of structural complexity of both the spoken and the written language is a mark of the degree of literacy. Spoken language tends to be additive and repetitive, and rarely displays relative clauses and recursion, if not being entirely devoid of them (Ong 1982; Chafe 1982; Kalmar 1985). Although the languages of some preliterate societies were not totally deprived of subordinate propositions, according to Kalmar (1985), in Inuktitut (one of the principal Inuit languages of Canada), relative clauses 
only appeared after this language began to be written. Compared to spoken sentences, texts contain much more subordinate propositions, without formal syntactic autonomy, and conversely much less coordinated propositions, and this makes them quite difficult to understand, except for high-level literates.

Indeed, syntactic processing in both comprehension and production of spoken sentences strongly depends on literacy, especially for higher levels of structural complexity. Here are a few illustrations of the fact that illiterates rely on the proximity of the agent and her (his) action. In production, illiterates do not say, for example, "The car of Mary stopped" (O carro da Maria parou), they say "Mary her car stopped" (Maria o carro dela parou). In comprehension, presented with sentences like "If the boys watching the girls play ball, who plays ball?" or "If the boys watch the girls play ball, who plays ball?", most illiterate participants responded "the girls" in both cases (Scholes and Willis 1987a,b).Their comprehension is thus based on the order and contiguity of the relevant terms.

Many literate syntactic constructions are opaque for people with relatively low literacy and some are only understood by experts. Comparing two groups of children, one school-going and the other nonschoolgoing, as well as two groups of adults, literates and illiterates, on oral tasks assessing their comprehension, expression, and grammaticality judgement of specific syntactic structures, Karanth et al. (1995) observed a strong effect of schooling and associated literacy in both comparisons. Dabrowska (1997) used sentences from Linguistic Inquiry (assumed to be normal English, by linguists), for example (this is one of the easiest to understand) "The mayor who Julie warned after learning the ex-prisoner wanted to interrogate managed to get away", then the participants had to answer a few questions (e.g., "Who wanted to interrogate someone?"). For the whole test, correct performance was only around $20 \%$ for the least educated group (cleaners and janitors of the University, with no more than 10 years of schooling), $40 \%$ for the undergraduate students, $60 \%$ for the graduates, and $90 \%$ for the lecturers in languages (see also Dabrowska and Street 2006; Street and Dabrovska 2010).

In addition, literacy has been found to enhance people's ability to predict spoken language, thereby also aiding spoken language comprehension (for a review, see Huettig and Pickering 2019). For instance, anticipation of visual objects (as evaluated using eye tracking) during listening to a sentence is better in high literates compared to low literates (Mishra et al. 2012). This effect is probably already an example of what Huettig and Mishra (2014) called distal effects of literacy. Indeed, it might be due to the fact that literacy trains core processes and representations involved in language prediction that are common to both reading and listening, allowing increased awareness of words as linguistic units (Kolinsky et al. 1987), fine-grained phonological representations and additional orthographic representations (e.g., Ziegler and Ferrand 1998). These proximate effects of literacy (Huettig and Mishra 2014) sharpen lexical representations and hence facilitate predicted representations to be retrieved.

Concerning high-level cognitive capacities involving transformative processing leading to new knowledge, huge literacy effects (when literacy is not just rudimentary reading but involves practice in interpreting written information) are observed on different kinds of reasoning, in particular when the inferences have to be made from propositions presented in abstract ways. Cary (1988) and Verhaeghe and Kolinsky (2006) reported in both illiterate and exilliterate unschooled adults extremely low scores in the first series of Raven's Progressive Matrices and in its easier coloured version, both of which require inductive reasoning from visual material; in the latter test, their scores were not above the percentile 50 of $7^{1 /}$ 2 year old children. Literacy provided our way of organizing and stabilizing thinking into reasoning. However, it is not necessarily the only way reasoning could develop. We should be modest enough to admit that, in the future, reasoning could develop in unsuspected ways under the influence of scientific and technological accomplishments.

Whether we assume or not that literacy is a necessary trigger of reasoning, the fact that there were so few attempts to examine the role of literacy in the development or learning of reasoning is astonishing. As if finding that literacy is a crucial condition for reasoning would be an outrage to the natural, in-born superiority of our species. If that thesis, which we advocated (Kolinsky and Morais 2018) after others (e.g., Counihan 2008; R. Harris 2009), were found to be supported by extensive evidence, it would not be a dismiss of the Darwinian vision of humanity. Rather, only of the pseudo-Darwinian rejection of the idea that 
culture, which is not our exclusivity, may be creative, and that the tools we have created and need to acquire through learning (among which, literacy) are now part of our nature.

In any case, all the effects of literacy we reported so far are remarkable given the fact that comparing contemporary literates and illiterates only provides an underestimation of the effects of literacy. Indeed, in our societies, a huge proportion of illiterates live among literate people and material literacy (the media, advertisements, etc.). This implies that contemporary illiterates have, in all likelihood, developed capacities sensible to literacy that illiterates in non-literate societies could not. Still, many of the potential effects of literacy on cognition remain unidentified, as the great majority of cognitive scientists, including those concerned by the theorization of language and cognition, has tended to neglect and even skip its role (Morais 2018). It was in particular the case of Chomsky, Fodor, Dennett, Searle, and of many of those who made exceedingly important experimental work on reading.

Without literacy, would it be possible to formulate and discuss concepts, to generate ontological and epistemological theories? And, although humans have experienced a large variety of social and affective states well before the invention of writing, was it not through reading that many of us greeted, felt and perceived such exceptional messages as those of Homer, Shakespeare or Kafka? Literacy is part of the air we are breathing, and this is the reason why most of us do not notice it.

Cognitive science thus presents two major characteristics: one is its capacity to open important questions about cognition; another is its capacity to not open some others, equally important, just because its questioning program is based on some postulates. One of these postulates is that literacy is not a major cause of cognitive development in our species.

Lastly, literacy does not yield only mental effects. It changes the world itself, materially, by contributing to both technological and sociopolitical transformations and revolutions. It is even involved in how we estimate such changes to be good or bad to us, as literacy may change our values and moral stances.

Obviously, not all forms of literacy have such effects. It depends on its degree and quality. For socioeconomic, political and ideological reasons, there is, even today, what has been called functional illiteracy or very low literacy on one side vs. very high literacy on the opposite side, with an extended continuum between those extremes. For sake of simplicity, we will often refer them as poor and rich literacy. The reason why, through our history and still today, the rich and powerful upper classes never gave up or accepted to share with the poor and powerless the best possible literacy education, neither just a good one, is that they know perfectly well that literacy is a much more decisive asset than mere physical force. Excellent schools are the privilege of the rich, bad ones the fate of the poor.

\section{The historical birth and progression of rich literacy}

In ancient Greece, until more or less the eighth century $\mathrm{BC}$, thinking, communication, and practical, instrumental knowledge, were served by oral language, whose intonational units may have provided sequential chunks for immediate memory. Relying on repetition, the language's prosody was propitious for dictation and for poetry.

Literacy emerged and developed quite fast following the import and phonetic adaptation of Phoenician characters to the Greeks' language. Transcribing oral poetry seems to have been an important application of the new writing system, and Homer's poems, transcribed several times and copied with modifications, have been the object of detailed analyses. In parallel, the alphabetic system was also used for prose writing. As the Attika society was quite unequal, as all the others since even before the invention of writing and until now, the majority of people only received very elementary education on reading prose, leading to quite limited comprehension and usage. According to Thomas (2009), education only enabled three levels of increasing "literacy" capability: name reading, list reading, and banking reading, thus all consisting of piecemeal reading and excluding continuous prose reading. Writing was almost out of reach. A minority of what she calls "officials' literacy", (probably between 5 and 10\%), issued from the aristocracy, received high-level literacy education, including writing continuous prose. Prose writing was considered by the sophists to be necessary for deliberative argumentation. Thus, the large majority of the citizens could only listen to such argumentative prose, in the assemblies and courts. However, literacy education may have expanded in the following centuries, 
especially with the advent of democracy in Attika at the end of the sixth century $\mathrm{BC}$ and in the course of the fifth century BC, but not to the point of dramatically reducing the literacy inequalities.

Missiou (2011) presented a somewhat different picture of literacy in Attika. Democracy was a creation of Kleisthenes, who ruled after the dictator Peisistratus. Contrary to the latter, who linked citizenship to land owning, Kleisthenes attempted to make all free men (women were excluded from citizenship) take part in the State institutions, in particular in the decisions on laws and decrees. He established a political and administrative organization based on the "demes", to link the town and the periphery and disperse the "tribes" (people of the same familial origin) in order to reduce the power of the aristocracy. $\mathrm{He}$ recognized the equality of political rights, to promote the emergence of a collective consciousness in the villages (where $85 \%$ of the citizens lived). The citizens of each deme were responsible for the local government, indicated their representants to Council of the 500, and had the right to take part at the Assembly, the Agora, which took the most important decisions. How is this linked to literacy? The 500 members of the Council were chosen by lot (every citizen had the same chance) in the tribes' assemblies, from the written lists prepared by the officers of the demes, so that each tribe, in number of 10 , had 50 members in the Council. All communications between the three levels, demes, tribes and Council, were written, and it was clear to everybody that those written messages could not be modified.

The Council was renewed every year, its president changed every day, and nobody could serve more than twice, so that almost all the citizens served at least once in their life. This allowed keeping the equilibrium among the tribes. A further institution, ostracism, of the responsibility of the Agora, which met with the minimal quorum of six thousand citizens (there were no more than 40 thousand free men in the Attika) may have contributed to develop at least a low level of reading and writing. Each citizen wrote on a broken potsherds (ostraka), which he deposited into the urn for his own tribe, the full name of the politician he would want to leave the Attica for 10 years.

According to Missiou (2011), the levels of literacy in Attika were highly variable, but a large majority would be able, at least, to read and write a little bit. In the absence of professional bureaucrats, the political life required enough citizens to elaborate motions and read proclamations (a mass rather than an elite literacy). How was this possible? Given that there were only few schools, it seems that most citizens learned to read and write during their political practices. "There were deme officials to whom administrative tasks based on literacy were assigned: secretary, copier, recorder, accountant, estimator." (Missiou 2011, p. 112). "Every year, in addition to the ten councilors who were elected as secretaries of the Council, all members of the Council were called on to perform tasks which unquestionably required writing and reading skills." (ib., p. 119). This and other arguments led Missiou to believe that "a clear majority of Athenians with full citizen rights served at least once in their lives on the Council." (ib., p. 122). This would be at least the case for the fifth century BC.

Missiou (2011) disagrees with W. Harris (1989), who considered that Athens was not a democracy of mass participation, with "approximately $15 \%$ of the adult male citizen population" (pp. 114 and 328). On the contrary, she insists on the fact that "all persons who had full citizen rights, thetes (labourers) included, could serve in turn on the Council", and that "service on the Council required all Athenians, including thetes, to be literate" (p. 130). It seems to us quite possible that many, perhaps even the majority of the citizens from Attika, including many of low class, had acquired some literacy ability by being involved in political activity. The crucial question is at what level. Were they fully skilled in terms of word and sentence recognition and written production? We have no data, of course, but think it more likely they were not. Were they able to critically evaluate and produce arguments? Perhaps only a few, among those who had attended schools with specific instruction oriented toward such capacities.

To sum up: have Kleisthenes' administrative reforms influenced literacy wide-spreading? Yes, it must have been the case for a majority of the people, but at a low level. Most probably, few were those who could compete, in literacy and, by consequence in reasoning and dialectics, to most of the members of the aristocracy. It is thus worth looking at what is known about literacy education in the fifth century BC in Athens and at the extent to which both thinking and reasoning had taken a critical and argumentative orientation.

It is admitted that in Athens only a minority received higher education, which included learning to write extended prose, while the majority had oral, poetry-based education. It is from among the highly 
educated that emerged the sophists who, for their part, involved themselves in what is called sophist education. Thus, written prose was combined with a formalized and probabilistic mode of abstract argumentation, during which opposite arguments were confronted. Students' mental flexibility was promoted by leading them to take any proposition from more than one point of view. This was an era of rationality: Protagoras and Gorgias, just a bit older than Socrates, were teachers in the middle of the fifth century BC, quite before Plato, who became a young man only at the end of that century. Living more than 2000 years later, we are impressed by the acceleration of the present scientific and technological revolution. In Greece, the reasoning revolution, precipitated by literacy, and steering to critical literacy, also developed in the blink of an eye, as commented by Leiper (2013): "It was in the fifth century BC that the male citizens of Athens experienced a radical shift from non-literacy to reading and writing." (p. 20); "Athenian education in the fifth century transformed its citizenry from 'pre-literacy' to varying degrees of literacy within a generation or two." (p. 30).

Poetry had an important role in Greece. The "Homeric epic is contextualized narrative thinking" (Leiper, 2013, p. 15). This rejoins some values underlying the modern global way of teaching literacy, according to which what is eventually important is the comprehension of the whole sentence and, even more, its comprehension in the framework of our social world. The word itself vanishes in the way, as just an accident. A distinct, controversial, idea is that prose may conflict with poetry. Leiper believes that prose literacy education inhibits in some way the inborn ability to 'think' in poetry and that some "cognitive abilities are lost by the acquisition of literacy" (p. 10). We doubt it is true. First, the ability to 'think' in poetry might not be inborn but triggered by very early oral and poetic enculturation. Second, if prose education inhibited poetic thinking, it would be difficult to account for the great literate poetry that was produced later on, since Dante who also wrote, in prose, an imponent political and philosophical treatise. ${ }^{1}$

\footnotetext{
${ }^{1}$ The writings of the Portuguese-speaking African novelists and poets Mia Couto and José Agualusa offer a contemporaneous demonstration of the wonderful interbreeding between poetry and prose (and even science).
}

We think the Athenian culture should not be characterized as highly literate and rationalist. It would be to take a (small) part for the whole. Like saying that our present societies are literate. It would, obviously, be wrong to call them illiterates: they are just exceedingly unequal. We concur with Leiper (2013, p. 22) when she says that Athens "was an historical example of a society where different forms of literacy education was a cause of societal and political disjunction as observed by Plato and others". And, again, we point to a likely source of our present antidemocratic, schismatic and violent society.

Our most advanced countries, those in which science is produced, are characterized by their strong inner inequalities in literacy, from illiteracy to the most critical and creative literacy, like Athens at its aureus age. The most obvious potential parallelism, still under the form of an alarm, is that our near future could evoke Athens, which, mainly due to its sociopolitical convulsions, disappeared for a long time from the historical scene. A second similarity is that, for the Greeks, "the most revolutionary impact in the early part of the century (the 5th) was that all levels of the population in Athens embraced the idea of literacy as a utilitarian tool rather than as a system with magical aspect" (Leiper 2013, p. 40). Similarly, for contemporaneous populations, literacy is crucial for our future, as attested by the nervous interest with which the rare statistical inquiries are followed and discussed.

While newspapers, books and even psycholinguistic and pedagogical publications insist, rightly, on the problems of minorities with special difficulties in literacy acquisition (dyslexics, autists, deaf children, children with ADHD or Down syndrome, etc.), there is an almost general neglect, from both the literate populations and the states, concerning the low-quality education for the mass of poor citizens and foreign immigrants, as well as for the young who, in vocational studies, do not progress much in literacy.

The literacy question is political, ideological, and socioeconomic. In Attika, the illiterate and poorly literate families did not have money to pay the schools or individual teachers for the education of their children. Presently, schooling is obligatory but many public schools for children from low social class tend also to be of poor quality. There is a hidden sieve which function is to let go down the children of the poor and keep those of the rich for the best schools, 
colleges and Universities. The system works perfectly well to maintain and widen the socioeconomic and cultural (and hence also cognitive) inequalities. Until when? This is the third similarity between the old Attika and our New World, knowing that the future is in our reason, values, hands and will.

\section{The power of writing}

Writing does not involve the same processes and has not the same cognitive impact as reading. Reading brings us what we did not know yet and may change our beliefs, but writing, more than allowing us to communicate at distance, changes our thinking, our reasoning, and, indirectly, our beliefs. Reading gives us material to exercise our capacity of critique, but writing, most probably, goes further and changes it.

Reading text, like listening to language, does not incite to ignore the meaningful context of words and sentences, nor to intentionally analyse grammar and the structures of language and thought. Yet this is exactly what writing does, and for abstract topics it may be necessary. Such analysis and decontextualization requires external solicitations and the will to take the written structures as an object of thought. In the course of continuous prose writing (obviously, we are not referring to mere transcription, but to composing through writing), we give order to our thoughts, and we analyse our arguments, our reasons. It is by practicing writing that we learn to ponder pro and contra arguments. Obviously, we are the first readers of what we write, we read it as we write it, often before material support, just in our head. During writing, we meditate, we speak with ourselves, we correct ourselves, we are Socrates' interlocutors and Socrates' himself (although at a much lower level), and by writing many hours a day, by questioning us through our own writing, we reach a higher degree of precision, both regarding the concepts, the connections between ideas, and argumentation.

An interesting question to be considered by each of us is suggested by the conclusion R. Harris (2000, p. 209), in Rethinking Writing, arrived at: that "for literate communities, it is not the written word which is the image of the spoken word, but the spoken word which is the image of its written counterpart". Although this statement concerns the word level, it is when extended prose writing is highly practiced that we, subjectively, experience it.
Writing is not just sequences of letters separated by blanks. Letters may have diacritics. There are also brackets, punctuation and quotation marks. All of them are important. They reflect the organization of the ideas and sentences, and the dialogue with others. Even if they do not read us. What is important is to have written for the others and make our thoughts accessible to the community, to everybody. Reading is solitary, writing is social and possibly widespread. But writing is also personal, it is, above all, our own writing, which we examine and can change until we feel satisfied.

When we recognize spoken words, their spelling is mentally activated (Ziegler \& Ferrand, 1988; for reviews, see Kolinsky et al. 2012, and Kolinsky 2015). Consistently, at the neural level, Dehaene et al. (2010) found activation of the area tuned to the recognition of written words (the Visual Word Form Area, VWFA) during an auditory lexical decision task. Word spelling activation occurs even when we are looking at a silent film without having to perform any task on an auditory stream of words (Pattamadilok et al. 2014). Not surprisingly therefore, we can memorize the speech we wrote better than the speech we had not written. This is possible because we, literates, "retain the spelling of words bonded to their pronunciations and meanings in memory", as shown experimentally by Ehri and Rosenthal (2007), for instance. It was also observed that Grade 5 children pronouncing aloud new words during text reading recall better the pronunciation-meaning associations and spellings of those words (Rosenthal and Ehri 2011). Moreover, spelling knowledge helps literates to maintain the representation of spoken words in short-term memory (Pattamadilok et al. 2010). Consistently, skilled elementary and middle school writers present larger working memory spans (e.g., McCutchen et al. 1994; Ransdell and Levy 1996), and from adolescence to an advanced age, working memory span predicts the structural complexity of texts even after reading skill, spelling, and handwriting speed are taken into account (Hoskyn and Swanson 2003). Writing capacity determines the output and the latter impacts the former (for a review, see McCutchen 2011). This holds also true for the increase of knowledge, thus long-term memory, and for the quality of reasoning and argumentation, as we will discuss later on.

Writing is also much more seditious than reading. This has been understood by the powerful across 
history and explains why the masses are usually allowed to learn to read, and even stimulated to do so, but not to write. Even nowadays, why do the Programme for International Student Assessment (PISA) and the Survey of Adult Skills (Skills Matter), both from the Organization for Economic Cooperation and Development (OECD), largely ignore writing abilities? For two reasons: because the overall results would be well below the mediocrity, and because writing ought not be encouraged. Exposing illiterates or poor literates (who usually are just able to read slowly and with errors, and do not write) to literate spoken language-what occurs, for example, when they listen to the governors' speeches or the news and debates through the main radio and television channels-makes them believing "blindly" what they hear. In the absence of writing practice, they have little chance of developing critical evaluation, and, if they do so, they remain unable to find good counterarguments. We will never have a real democracy, whatever the country, if a culture of writing - writing that contributes to cognitive development and to the mastery of critical reasoning-is not invested for all the people.

\section{Critical literacy}

Critical literacy is literacy activity that, whatever the means (written, spoken, imagistic, or any else), includes a component of verification of the conveyed information for its truth or appropriateness, followed, if it were the case, by precise identification of its inaccuracies, incorrectness, and possibly falsehood. In these cases, critical literates are expected to provide corrective or alternative proposals and support them by arguments.

\section{How widespread is critical literacy?}

The OECD studies PISA and Skills Matter, which report on 15-year-olds as they approach the end of compulsory education and 25-to-65 years adults, respectively, include some information on critical literacy, yet based mainly on reading comprehension. The latest PISA study does contemplate argumentative writing, arguing that "The PISA 2018 reading framework considers writing to be an important correlate of reading literacy. However, test design and administration constraints prohibit the inclusion of an assessment of writing skills, where writing is in part defined as the quality and organization of the production. However, a significant proportion of test items require readers to articulate their thinking into written answers. Thus, the assessment of reading skills also draws on readers' ability to communicate their understanding in writing, although such aspects as spelling, quality of writing and organization are not measured in PISA." (OECD 2019, p. 49). In other words, the PISA 2018 assessment still focusses on reading comprehension, considering that spelling and grammar are irrelevant, although "open constructedresponse items are particularly important to assess the reflecting and evaluating process, where the intent is often to assess the quality of a student's thinking rather than the student's final response itself" (ibid.). Would it be useful to make PISA's team remember Boileau (1674) verses and Horace's (c. 19 BC) famous adage about the relations between thinking and writing? Boileau wrote "Ce que l'on conçoit bien s'énonce clairement / Et les mots pour le dire arrivent aisément." (in English: "Whatever we well understand we express clearly, and words flow with ease"), and Horace (translated by Blakeney 1928) explicitly stated that "To have good sense is the first principle and fountain of writing well". Thus, although it is logically possible to write well while having confusing ideas, if Boileau and Horace were right, according to the inference rule called modus tollens in propositional logic (if an argument is true, then so is its contrapositive ${ }^{2}$ ), confusing writing necessarily implies confusing ideas, namely misunderstanding.

In any case, in the most performative countries, there would be around $30 \%$ of critical literates, and, in the poorest, less than $10 \%$. If a more demanding criterion were used, the critical literates would approximately correspond to the countries' elites.

The notion of critical literacy is considered differently depending on the authors' objectives. Our objective, as we said above, is to characterize critical literacy as cognitive processing while taking into account the social and cultural dimensions of this

\footnotetext{
$\overline{2}$ The contrapositive of a statement has its antecedent and consequent inverted and flipped. For instance, the contrapositive of the proposition "If something is a cat, then it is a mammal" is "If something is not a mammal, then it is not a cat").
} 
processing. As a consequence, we will not consider here the vast educational and pedagogical literature.

Critical literacy is crucial for everybody, including, on one side, scientists, jurists, journalists and other literate people who have constantly to distinguish truth from lie and estimate truth probability, and on the opposite side, non-literates, either poor readers or illiterates, all exposed to oral information whatever its remote source.

Everyone should be able to protect her or himself from, for example fake news, whatever their intention, and to all sorts of unintentionally spread false information. Many studies have now documented the widespread tendency to believe rather than disbelieve what we do not know precisely. For example, among young Austrians, $60 \%$ of the secondary school graduates and $30 \%$ of the university graduates accepted as more sure than false that we use only $10 \%$ of our brain (Swami et al. 2012). More seriously, many people, especially vegetarian, believed the press-released new that meat eaters are more selfish and less social than non-meat eaters. Its origin was a "scientific" paper that the author tried to get published as a real finding but was checked and rejected by the reviewers (see description in de Bie et al. 2015). Numerous people still believe that the Earth is plane and that we were created by God less than 10,000 years ago (Silva and Prado, 2010). And during the football world cup several Dutch players bought bracelets Power Balance they believed to afford force, equilibrium and agility, which a subsequent study showed to produce no effect, not even placebo (de Bie et al. 2015). The lack of rigor of the press, allied to the desire to attract readers, gave popularity to pseudoscientific claims like those diffused in the book Teaching the brain to read, by Dr. Duncan Milne (2005), which asks questions such as "how do we teach reading to a group of different brains or to a specific type of brain?", and "which sites in the brain must be aimed at for remediation or accelerated learning?".

Even bright scientists commit grave errors, as science is permanently correcting itself. More precisely, given that science is not an actor but the outcome of scientists' work, instead of referring that scientists are revealing the truth, which is only partly right, one might say the other part of the truth, that every scientist is pointing out the previous ones' mistakes. All this is critical literacy, in this case applied to science. Yet many scientists seem unaware that science is a form, perhaps the most extraordinary form, of critical literacy. Strangely, some of the most brilliant cognitive "brains" do explain cognition without referring how much both cognition itself and their statements about cognition are due to, and impregnated by, literacy tout court. One of us (Morais 2018) mentioned several of those people, and, together (Kolinsky and Morais 2018), we attempted to unveil this blinding process.

\section{Brief historical note concerning critical literacy}

Socrates seems to have been the first great critical literate. He may not have called himself "critical literate", mainly because, while being literate and aware of it, this qualification was probably not among those he praised the most. However, one may say that he was critical literate more often than literate tout court. At Socrates' time, literacy was a power unequally distributed and, quite unjustly, it was his critical literacy that condemned him to death.

It seems that during the Paleolithic, power belonged only to the men, but in a rather equal way. With the invention and subsequent development of food storage, other animal's rearing, agriculture, pottery and, later, metallurgy and urbanization, groups and societies fragmented into classes, rich and poor, nobles and plebs. It is in that situation that writing was invented and the Greek-formerly the rich aristocrats, later a great part of the freemen-largely benefited from it.

Literacy extended in the world, mainly in China. In Europe, in the last thousand years, literacy greatly increased, but it was in the interest of the powerful not to raise it to the level of critical literacy. It is since the last 500 years that critical literacy mainly developed, although it was attacked many times. A double line of discoveries emerged, one of space-other continents and people; the other of knowledge-science, i.e. critical literacy in the scientific domain, which is not recognized as critical literacy. Even the power of the rich nobles or kings and of the churches became the target of critical literacy. With some success.

Could it be a reason for underestimating the role of critical literacy? Critical literacy is itself a power: a power to make knowledge and technologies progress, and a power of two faces, each criticizing and condemning the other, for disputing positions in the social and political arenas: one to keep power, legal 
and strong, oppressive and repressive; the other to equilibrate power if not reverse it, illegal and weaker, except in rare crucial moments.

The two critical literacies, the scientific and technological (one might associate to them the philosophical, the juridical, the economical, the media, etc., all acquired in the academies), and the ideological and political, are not independent of each other. The reason for this is that the same actors, namely the literates, are involved in both, although in general with different degrees of involvement. This difference is crucial.

Indeed, the scientific and technological literates, whatever their ideological and political options, are deeply involved in their literate work and strongly depend on the established power to have access to their working instruments. Among the scientific literates, it is those who are involved in the human and social sciences who, in a larger proportion, are more concerned by the critical literacy of the established power.

Moreover, critical literacy requires free thinking, and free thinking may be incompatible to some extent with professional activities that depend on the established power. Anyway, critical literacy also requires cognitive capacities that have been and remain nurtured by a consistent involvement in literacy activities, in particular the capacity of reasoning.

\section{Writing and critical literacy}

Writing not only contributes to literacy but-as we proposed above-is intimately linked to thinking and reasoning. We, literates, when we think and reason, are perhaps "writing" in our heads, even if we do not hold a pen in our hand nor are in front of a "Word" page. Maybe we "write" our thoughts, because these must have the content and the formal properties of literate thinking. If you stop reading us exactly now and attempt to formulate a replica in your head, you may find that you mentally write your thoughts from left to right. Especially if you are supposed to write it afterwards. This should not be surprising if we consider that when we hear speech, we, literates of the Latin alphabet, are influenced by the typical directionality of our script, from left to right. We already mentioned this phenomenon first reported by Bertelson (1972), but we will detail it now with the purpose of discussing what could be this "mental space" where, apparently, we would "write" in a given direction.

This spatial effect was observed using an experimental situation devised by Fodor and Bever (1965). These authors found that when we hear a spoken sentence and a click that occurs at some point, we judge the click as occurring before its actual time of occurrence relative to the sentence, a so-called negative error. And the error is more negative when the click is presented to the left ear and the sentence to the right ear than in the opposite situation. Bertelson (1972) observed this negative error for French sentences in both French-speaking Belgian students and Israeli students. However, Israeli students listening to sentences in Hebrew showed the opposite effect: The error was less negative with the click on the left ear and the sentence on the right. Only the difference in the direction of reading can explain this reversal. The script spatial direction and hence our reading and writing routines influence the way we listen to spoken language.

The directionality of our writing system also influences the way we scan (nonlinguistic) visual information (e.g., a picture array), an effect that is absent in illiterates (Padakannaya et al. 2002). More generally, script directionality influences visuospatial attention (e.g., Chokron and Imbert 1993; Rinaldi et al. 2014) and the spatial representation of actions and scenes, when subjects have to draw or arrange toy figures in response to spoken descriptions (Dobel et al. 2014; Roman et al. 2013). It also induces spatial biases at abstract representational levels. Indeed, literates activate spatial representations consistent with the directionality of their script during their temporal reasoning. For instance, those using the Latin alphabet organize from the left to the right the development of the egg to chick and hen, but the Hebrew do it in the opposite direction (Fuhrman and Boroditsky 2010), and the Taiwanese from top to bottom (Bergen and Chan Lau 2012). Manual gestures when referring to past or future also reflect writing directionality (Ouellet et al. 2010).

We mention here those data on the unconscious impact of literacy on our behavior because they are relevant for a particular case of critical literacy, which we might call auto-critical literacy. Auto-critical literacy is rendered necessary by the fact that our thinking and reasoning are, in many respects, 
influenced by the instruments of literacy—as shown above, by writing itself.

To the best of our knowledge, no cognitive scientist has tried to find if we "write" our thoughts from left to right (for readers of the Latin alphabet, but for others, from right to left, or top to bottom). Let us assume this is true. If so, we might also expect to keep in our memory, in an unconscious or subconscious way, for perhaps just two or three seconds or even less, a "written" trace of what we heard. In the same way as we are not aware of having an echoic and an iconic short-term memory. The difference is that it would suppose an automatic transliteration of speech. Would it be so surprising when we know that, you and us, have a long practice of writing, in particular writing well-structured scientific prose? Just only one step more and we would accept that our writing capacity and habits, so rooted in our mental system, may influence our critical judgments in situations where these are expected.

We are aware that there is no demonstration of it, but you will agree that nobody tried to check, and for one very simple reason: Very few researchers believe in the power of literacy, in particular of writing, on our introspection. It was also totally unexpected that a purely auditory lexical decision task would be sensitive to our mental representations of the word spellings (Ziegler and Ferrand 1998), an extraordinary discovery we already mentioned but that has not received until now the interest it deserves, although it has been replicated in several other languages (e.g., Portuguese: Ventura et al. 2004; English: Ziegler et al. 2008) and across several tasks (e.g., semantic and gender decision: Pattamadilok et al. 2009; Peereman et al. 2009).

To illustrate how writing might influence critical literacy, we will jump from science to a social domain in which critical literacy has since long a huge role to play. We recall that, in Greece, the sophists were strongly concerned by pro and contra argumentation in courts, and that the literacy education they promoted involved this kind of critical thinking and reasoning. We will present below, with our comments, a brief synthesis of an opinion paper written by Oldfather (2008), which raised this relevant question regarding situations of critical literacy in the domain of Law and focused on how writing influences cognition and judicial decisions. We think this discussion may help cognitive scientists to become aware of the fact that writing - and literacy in general-has not received the attention it deserved in their own domain (which also constitutes, in fact, an example of critical literacy...).

How do I know what I think until I see what I say? (italics from ours), is a thought attributed to many writers (for example, Raymond Carver and Oscar Wilde) and famous people (Winston Churchill). Writing is not mind-wandering, it is an engagement. And Oldfather (2008, p. 1284) signals that a similar feeling is evoked by the phrase it won't write, which refers to situations where the result the judge initially thought appropriate turns out, upon an attempt to justify the result in an opinion, to be unacceptable. As suggested by Oldfather (p. 1285), "This insight accords with longstanding conceptions of the judicial role, in which reasoned analysis stands as the core feature of legitimate judging. It also suggests the possibility that preparation of a written opinion might be deemed an essential component of a legitimate judicial decision". This would be due to the fact "misconceptions and oversights of fact and law are discovered in the process of writing" (Baker 1993, cited by Oldfather 2008, p. 1284), as "the written form of an argument encourages some degree of critical detachment in the writer, who in reading what he has written will be wondering how an audience would react. Many writers have the experience of not knowing except in a general sense what they are going to write until they start writing." (Posner, cited by Oldfather, p. 1284). Hence, according to Oldfather (p. 1285), "if writing truly does lead to better reasoning, and if the application of reason is the defining feature of the judicial role, then it seems to follow that the process by which judges reach decisions ought to incorporate writing. (...) From the perspective of the legal academy, the written opinion represents the archetypal judicial act." (p. 1285).

An important issue concerns the relations between deciding and justifying. Oldfather (2008, p. 1298) mentions R. Wasserstrom (1961), according to whom the first component of the judicial process, "making a decision", which refers to the "process of discovery", and the second component, justifying the decision or "process of justification", have no necessary relation to one another. Why? Because a judge "might stumble onto a decision by chance or might be inspired by something completely external to the law, such as a flash of insight while gazing at the sunset." (p. 1299). Oldfather then introduces Golding (1986), who "further develops this conception of judging by analogy to 
the process of scientific discovery" (p. 1299), recalling the chemist von Stradonitz's account "of how the idea of representing the molecular structure of benzene by a hexagonal ring came to him while dozing in front of his fireplace and seeing the flames dancing about in snake-like arrays". In a similar fashion, a judge might have the resolution of a case occur to her/him in a flash of insight triggered by some stimulus external to the law. But, Golding reasons, the appropriateness of that result can only be demonstrated by reference to justifying reasons. These serve a function analogous to experimentation in science, namely they provide a mechanism for testing the validity of a hypothesis. "The "testing" of a proposed decision (...) occurs (...) in the argument that shows that the decision can be inferred from correct propositions of law". Explanatory reasons are irrelevant, only count justifying reasons: the crucial question is whether the given reasons are adequate to establish the conclusions, and not whether they were the products of hunch, bias, or personal value-predisposition" (Golding 1986, cited by Oldfather 2008, pp. 1299-1300).

"It won't write". What does that exactly mean? Oldfather (2008, p. 1303) explains: "a result or line of reasoning that seemed appropriate at one point (...) no longer seems so attractive when the judge attempts to transfer it to paper. Perhaps the authorities the judge thought justify one result turn out instead to justify another. Or perhaps writing reveals gaps in what appeared to be an unbroken chain of logic." Oldfather (pp. 1303-1304) refers to the well-known work on literacy and cognition by Goody (1977) and Ong (1982) to recall that preliterate societies lacked a system of law and that "every modern legal system utilizes written codes and records". He stresses the fact that written words "can be more easily manipulated in thought", that the reader "need not devote great effort to storing the content of text in his memory", expending "more energy on understanding and assessing", and that "written text may be essential to (...) syllogistic reasoning, which figures prominently in legal discourse". Inspired also by psychologists such as Kellogg (1994) and Bereiter and Scardamalia (1987), Oldfather defends the idea that sophisticated writers engage in knowledge transformation: unlike unsophisticated writers, they are not simply engaged in knowledge telling; they engage in "simultaneous acts of problem-solving" (pp. 1307-1308). For them, "the process of writing involves the transformation of thought" and "the act of writing involves the reworking of thought", and writing would thus change thinking in a stable way.

We agree with this idea, because through writing one acquires (1) further knowledge, (2) a new kind of representation, and (3) processing strategies associated to writing. However, we lack evidence, especially on the latter two points, and much work would be necessary to know how exactly writing changes thinking. Although we acknowledge that "our understanding of the relationships between writing and effective cognition remains in the early stages of development" (Oldfather 2008, p. 1342), we believe that we should give up the idea that writing is nothing but writing, and study more systematically its impact on the whole cognitive system.

Our main arguments supporting our belief that literacy, especially through writing, changes thinking in a non-reversible way are the following. First, literacy provides schemas to organize mental arguments (the case of syllogisms in deductive reasoning is a flagrant one) and to organize knowledge (as in dictionaries or encyclopedias). Second, literacy provides what some cognitivists (e.g., Gazzaniga 1989; 1995) call our internal interpreter, which functions also with oral language and in relating actions and their effects, according to causality, feature sharing, etc. Third, literacy provides a representational stability and even permanence that cannot be achieved through oral language, and this is crucial for enlarging the processing span of thinking and reasoning.

All these literacy advantages lead us to believe that we, literates, when we think and reason, are already writing in our heads: We "write" our thoughts, because these must have the content and the formal properties of literate thinking.

Below we confront three distinct social practices and research domains, all of which revendicating to be covered by the same term, critical literacy, which unfortunately became a gaily colored umbrella.

\section{Critical literacy in the educational domain}

The term critical literacy has been used since the 1980 s to refer to research on educational practices allowing children, adolescents and adults to develop literacy invested by politically progressive ideals. "Literacy is a political background" is the beginning of Bishop (2014) paper on this approach. The educator 
is an activist and the researcher does explicitly name the domain as "cultural studies". Bishop (p. 51) cites Anderson and Irvine (1993) definition of "critical literacy": "learning to read and write as part of the process of becoming conscious of one's experience as historically constructed within specific power relations". Education is inspired by justice (it shall, indeed), research occurs in the context of activism (it can be useful) and both concur to develop sociopolitical and activist identities in youth (it is better than cynical "apolitical education"). All this is assumed "to support literacy practice", and it is this, together with the idea that learning to read and write is part of a conscientization process, that inverses the relation between the mean (literacy), which is general, and the end (making an option), which is necessarily particular. We should want literacy to enable people make choices, not the reverse. We need eyes to see the world from all perspectives, not receive eyes preadjusted for one perspective. Let critical literacy be genuinely critical!

"To understand and practice reading and writing in ways that enhance the quest for democratic emancipation" (Lankshear and McLaren 1993, p. xix)" is acceptable, but only if the understanding and practice of reading and writing leave the literate individual entirely free to evaluate and judge what "democratic emancipation" precisely means in its context and whether it deserves or not to be endorsed. This is the right response to the traditional literacy curriculum intended to form citizens for the protection and consolidation of the established socio-political system. We agree with Lankshear and McLaren in that critical literacy includes discussing how societies became unequal and how the education system implemented by the political power preserves the privileges and prevents generalized access to culture. They rightly unmask both the liberal form of education that recognizes intellectual freedom but avoids contradiction, and the political pluralism that tolerates the diversity of opinions but closes the way for stopping social discrimination. For our part, we think that critical literacy, to be genuine and operative, must have access to the educational and institutional means allowing a rational and potentially radical change of society if it points in this direction, in the absence of which revolution becomes the only way out.

In many countries, the Freirean pedagogy conceptualized and put in practice by Freire and Macedo
(1987) constituted a major stimulus for the expansion of the critical literacy theory based on the notion of "conscientization", which requires introducing social and political literacies in the curriculum. Freire and Macedo claimed the necessity of a critical literacy revealing and naming the conditions of oppression and leading to direct emancipatory action via "transformative praxis". Under this view, literacy is not only critical, it is also transformative, it changes the world. The Freirean pedagogy, applied at the beginning of the 1960s by young students to a large group of completely illiterate adults in Angicos, in the north of Brazil, and praised by the President João Goulart (Jango) before the military coup, was certainly insufficient and could not yet be supported by the advances in the cognitive psychology of reading that occurred later on, in the beginning of the 1970s. Critical literacy may be a dangerous enterprise, in particular for the poor learners: Some went in jail and were tortured, others had to escape after burning their exercise books. That was the material effect of the Freirean pedagogy, but the notion of "transformative praxis" and especially the consecutive projects of critical literacy for the people it inspired may be taken back and largely improved in accordance with the last half century huge advances in the cognitive science of literacy. Science offers now a way to ground a transformative critical literacy praxis. Will the educational class take such a major challenge up?

Many writers on the education of critical literacy reduced this to a strictly sociopolitical issue, the unique solution of it being the Freirean pedagogy. Indeed, critical literacy and educating children and adults is an important sociopolitical issue, but it is also important for personal and other social (not necessarily political) reasons. Regarding the Freirean pedagogy, centered on political conscientization, not only it had and still has a laudable aim, but it also nourished the hope of many poor and exploited communities to empower themselves and become actors in many countries that had been colonies or are still in the decolonizing process. In reality, beyond formal political independence, both South and Central America, with the exception of Cuba, and, with small differences, all African countries, have been and remain economically and politically dependent of the US and of the stronger European States. One may thus understand quite well the hopes raised by the Freirean Pedagogy of the Oppressed. And, as among the North 
American low social class people, there were and are many Afro-Americans (it is worth always remembering their slave origin) and Latinos (from many countries in which the US intervened militarily or supported accomplice governments), it is quite normal that Paulo Freire ideals and ideas had penetrated many US schools and influenced conscientized educators.

Being critical literacy our subject, it is reasonable that we criticize here some aspects of how critical literacy is presented by adepts of the Freirean pedagogy. We take, as an example, a paper by Lee (2011), a US university professor in language education from Virginia whose intention was to explain teachers which myths about critical literacy they should unlearn. We will discuss here two myths among the four discussed in that paper.

Myth 1 is Critical thinking is critical literacy, and, for Lee (2011), the reason why this is a myth is that critical thinking focuses on logic and comprehension, whereas critical literacy focuses on "dominant ways of understanding the world and unequal power relationships" (ibid., p. 97). We agree that these are two different concepts, but for different reasons than Lee. First, critical thinking is not critical literacy when it is not mediated or influenced by literacy, in other words critical literate thinking is critical literacy. Lee's definition is based on the object of the mental activity (logic vs. social relations) whereas for us the distinction is based on the kind of cognitive capacities (nonliterate vs. literate) involved in thinking. Second, for us, critical literacy can operate on social relations but also on many other issues. Third, Lee's view implies that illiterate people could not think about social relations. Our personal experience of some totally illiterate people (in the sense of totally unable to read or write) showed us that not only they can think about social relations critically, they can also be activists and discuss and cooperate with literate activists who do not intentionally communicate literacy to the former except through their inability to talk in a purely illiterate mode. So, concerning Myth 1, we agree on only one proposition: critical literacy should not be reduced to critical thinking, because critical literacy is more powerful than critical thinking and operates on many other issues than just social relations.

Let us look now at Myth 2: critical literacy is meant for high ability students (Lee 2011, p. 98). It is a myth for us as for Lee. On the contrary, it is a belief and a praxis for those educators who, consciously or not, embrace the idea that critical literacy and even literacy tout court, are conditioned by innate high ability or intelligence. The present authors (and presumably Lee too) believe that the huge majority of children, if they are given the appropriate learning conditions of learning, can develop and make use of critical literacy. We do not know what the governments and their delegates for educational issues think about it, but we infer from the consistent practice of orienting the children and adolescents born in upper class families (of course not those of lower class) to the best schools, colleges and, later, universities, that they believe much more on the impact of high-level education than on the effects of innate high level intelligence. More important for the present purpose is not the presumed "high intelligence class", but the presumed "low intelligence class". Freire (1984) wanted the working-class peasants of Angicos to learn generative words (no relation at all with generative grammar). Freire was thus targeting elements of the discourse which are perceived and understood during oral language comprehension, but not as having specific identity, role and meaning, and that we only think about when we focus on them. Freire wanted thus to call their attention to words, and through words to make them infer concepts. This is typically a literate procedure. In fact, the method consisted in making the illiterates read and write isolated words, and then analyze and discuss the concepts the words denote, namely their lexicalized meanings. They were learning literacy through a few elements of literate meaning on which it is possible to think and, why not? also reason. Of course, these were just a few insights, moments of vision in the obscurity, there was no way to read words or sentences never encountered before. However, given that for us there is no literacy if it is not complete and autonomous, in the sense of based on skilled text reading and writing, the way for personal critical literacy is closed. Freire either was not aware of this imperative or had no time to care about it. We should not blame him. According to Pelandré (1998; 2002), who interviewed Freire not long before his death, he modestly told her not knowing the methods of teaching to read. He was not a cognitive psychologist or a teacher, he was a sociologist. And he was right showing the illiterate peasants that behind words one finds concepts, and that these open the way to critical literacy. There are cases of illiterate adults who acquired literacy and were able to write about their 
personal and social life (Morais 2018). So, the way to critical literacy is not closed to the illiterate adults.

Among the educational critical literacy theorists, $\mathrm{H}$. Janks, although less known than Freire, strongly influenced education in another country with a colonial past, namely South-Africa in the post-apartheid period. To her, the process of enliteration (Janks 2013) involves not only to acquire and develop the cognitive capacities involved in literacy and critical literacy, but also to become aware of the interactions between literate cognitive activity and other personal territories, desire and identification, pleasure and play, taboo and transgression (Janks 2002). Given that "critical literacy is essentially a rationalist activity", she began to address "the non-rational investments that readers bring with them to texts and tasks" via "playful advertising texts that work with humor and the transgressive in order to consider the role of pleasure rather than of reason" (Janks 2010, p. 7). Inspired by Freud (1916), she asserted that "Jokes and humour allow us to rebel against authority institutions or views of life (...) and to unmask deception" (Janks 2010, p. 220). In Janks (2002), she referred to a personal experience which she felt when, after returning from the US where her son's wedding was celebrated, the $9 / 11^{\prime}$ s attack happened. Being usually critical of the US, she nevertheless understood she could not engage intellectually with the issues, "as if I had no access to my own rationality". It was only by recognizing her unconscious identification with the US that she could recover her critical abilities: "For the first time, I realised the extent to which critical discourse analysis preaches to the converted" (ibid., p. 21).

Critical literacy is more than reason. It must be rational, but of a rationality that accommodates the passions, the collective and the personal ethos. Further, critical literacy must integrate science (scientific literacy) and art (fictional and artistic literacy), this being the creative and aesthetic rendition of reason, passion and imagery engagements.

\section{Critical literacy in social theory}

In the theorization of social sciences, much more than in research on precise social topics, we noted the uncomfortable feeling that one does not know exactly what is reality, what is a fact, as these appear to be constructed through language and discourse, and, at a deeper level, through social theoretical literacies.
These would require an overarching critical literacy, much more methodological than engaged in a particular theoretical orientation, but to our knowledge it has not been formulated. It would have been possible if social cognition had been prolonged by social metacognition, which would require investigating how the concepts and theories of social cognition, necessarily literate, are influenced by literacy. As it did not happen, we are confronted with multiple critical literacies of the human social dimension. As experimental cognitive psychologists who study literacy, we try below to identify cases of literacy and critical literacy that impact social theorizing.

Human social facts involve actions, or absence of action, repetitive or not, between people who have or not conscious or unconscious disposition to act, in some relational context which can take many forms; they can be well perceived or not by the actors. They can even involve physically only one person provided they occur in a socially determined context. They can be preceded, accompanied and/or followed by overt or covert (mental) language events, and these can be expressed in many ways, by bodily or manual gestures, speech sounds, sometimes reading or writing, and even cry or laugh. Assuming their reality has been proved, it may be difficult to infer from them both their true meaning, which may depend on nonvisible social factors, and their relevance, i.e. their potential effects. This extremely varied and complex framework may explain why social scientists have attempted, since less than three centuries ago, to account for social acts that are socially relevant by referring them to social "structures", and, in the course of this process, the concept of structure became the root of the social theory now called structuralism. The idea and the word "structure" were already present in Marx's sociopolitical work (perhaps even before Marx), later in Peirce's semiotics and in de Saussure's linguistics, and it seems that the theory of structuralism was coined by Jakobson in 1929. The idea was that both social relations and the equally social but specific linguistic abilities reflect peculiar deep structures.

The structuralist theory could be formulated because the concept had been engendered. The concept of structure itself (the word is of Latin origin, designating "place together", "build"), as abstract mental representation of a sentence, would have been unthinkable without literacy. In illiterate societies 
there was no distinction between the name (the word) and the denoted object, and even contemporaneous illiterate adults who live among literates attribute to the signifier the characteristics of the signified, taking for instance the physical size or emotional importance of the concept for the name's length (e.g., for many of them the word "cat" is longer than the word "butterfly", cf. Kolinsky et al. 1987). In her comprehensive review, Adams (1990, p. 298, italics are ours) wrote: "Surprisingly as it may seem, the evidence concurs that children are not naturally prepared either to conceive of spoken language as a string of individual words or to treat words as individual units of meaning." Illiterate adults and preliterate children can however access functional word groups in oral sentences: if presented with, say, "the old boy runs in the street" and asked to break it into small pieces, the most frequent answer is "theoldboy-runs-inthestreet", indicating they are aware of the corresponding functions (if asked to break it into even smaller pieces, they segment into syllables). This has been observed repeatedly in preliterate children (Karpova 1966; Kurvers et al. 2007), illiterate adults (Cary 1988; Kurvers et al. 2007) and schooled but nonprofessional people (Davis 1997).

What literacy does is to create and/or make apparent the structure of propositions and its internal concepts. If we are literate, we can easily distinguish words both in spoken language-but only if we know the language and hence recognize them-and in text, in this case because we see the blanks between words (we will see that separation cannot be the only wordiness information). In some languages, for example when the hyphen is currently used, there may be some ambiguity, but the blank space tends to be the criteria. This has been clearly shown by Scholes (1993): When asked to circle the individual words in written sentences such as "Edward likes togo tothestore", second graders consistently circled the strings bounded by spaces, a response that was not observed anymore in fourth graders, who ignored the erroneous spacing and made the correct circles. Yet, although the notion of word is usually acquired when one learns to read and write, it can be acquired also by other means, inspired by the physical word separation in writing (e.g., Cassata-Widera 2008).

Literacy has a history (past, present, and unpredictable future), which depends on at least three nonindependent dimensions of the human societies: technology (handwritten; printed; digitalized), socioeconomical organization (hereditarian; capitalist from industrial to financial and manipulative of will), and educational policy (restrictive; highly selective but pseudo-universal). The historical changes in those three dimensions engendered forms of literacy (the mental capacities and representations directly or indirectly supported by the abilities and activities or reading and writing) that may be characterized as mental structures. The products of literacy are inspired by such mental structures, but depend, for a large part, on human creativity and aleatory facts. The concept of structuralism is itself a product of literate thinking that takes the occurrence of regularities at different levels for an all-encompassing and inevitable theory. We, being critical literates, recognize the accurateness of the concept of structure for describing and even explaining many social phenomena, including language, and literacy itself, but without embarking in structuralist theorizing.

Beyond the epistemic value of the concept of structure, there is a further important issue: whether and to what extent this and other literate concepts may have a strong and durable influence on events and on material reality. Literate people tend to refer to their concepts to guide their behavior, and behavior inevitably modifies material reality. Thus, literacy is not just a form of thinking, it is praxis, it projects onto the physical world and changes the world's course. How could it not be so if the tandem sciencetechnology is definitely the expression of the coupling of literacy with creative thinking twisted by the literate elites' sociopolitical aims? The last phrase must be spelled out: society being a mess made of classes without clear boundaries, the direction it takes, and science-technology with it, are actually decided by the leaders of the dominant class. Only in situations of huge crisis may the non-dominant classes hope their words blow the material reality and inflect, or more dramatically, shift the world course.

In the Preface to A Contribution to the Critique of Political Economy, Marx wrote: "In the social production of their life, men enter into definite relations that are indispensable and independent of their will, relations of production which correspond to a definite stage of development of their material productive forces. The sum total of these relations of production constitutes the economic structure of society, the real foundation, on which rises a legal 
and political superstructure, and to which correspond definite forms of social consciousness" (italics are ours). Structure was a chief concept in Marx's theory of the society, and some social scientists decided to consider Marx, retrospectively, as the first structuralist. Indeed, later, in the twentieth century, this concept inspired the "Structuralism" theory in linguistics, which quite rapidly became a social theory, valid for human sciences in general according to many thinkers. The idea has been attributed to de Saussure, but, amazingly, in Course in General Linguistics, the book compiled in 1916 from two of his students' notes on his lectures, the word structure is never used, as if it were possibly to approach language scientificallyi.e. through scientific literacy — while ignoring literacy and, in particular, scientific literacy. The main concepts of this book are speech, already an abstraction from speaking, which is the individual act, and language, which resulted from a social contract and is a system of signs linking "psychological parts", meaning and sound-images, to express ideas. Writing is also a system of signs expressing ideas, as symbolic rituals, military signs, and so on, but language is the most important of all. According to de Saussure, the science of signs did not exist but should be created as a part of social or general psychology, and he proposed to call it semiology, from the Greek semeion, "sign". Linguistics would be just a part of semiology and the laws of semiology would be applicable to linguistics. The linguistic sign does not unit a thing and a name but a concept and a sensory sound-image. About the concept, de Saussure only said that it is "generally more abstract". Until now, no trace of literacy, except the fact that written signs correspond to language ones. Their peculiarity is to be sensorial as they can be seen.

De Saussure was right, except that he did not think that written signs could be, as indeed they are, cognitive tools, in the same way as two signs, 0 and 1 , are tools for artificial systems created by our cognitive system. Whether the sign is spoken or written seems at first to be irrelevant. Nonetheless, the spoken sign disappears as immediately as it is produced, leaving just an echo or a remembrance conflicting with other remembrances, while the written sign stays out there, is permanent, out of us and available to us at any moment. Moreover, the written sign is bi-sensorial (it is visual and evokes a "sound", in addition to evoking the motor act of its production), which allows to double or so our memory capacity.
Yet, these are not the most important differences between the two sign systems. The crucial difference is that written words are not single events. In written sentences they are at the same time single and members of a sentence and, in a world of written sentences, their meanings and functions can change. There is time to compare them, find differences and similarities, and establish links from which to infer abstract concepts. All along our thinking, the written words, the written sentences remain out there patiently, and our brain, no less patiently, lets us (our thinking) vogue from concept to idea and from idea to concept and discover new stars. Literacy in action is literate thinking, and literate thinking is exactly that: a mental travel in a sky staked by rules, dreams and insights through three sorts of constellations: what, why and how.

Chaffee and Lemert (2016) distinguished two opposite reactions to structural principles. Orthodoxy "arises when a dominant structural principle is reinforced by long-valued beliefs that cause practitioners to resist innovations that would threaten the dominant understanding of the field". Scandal, in contrast, "arises, as in all organized human practices, when defense of a structural principle originates in rank ideological or financial interests." (p. 125). Chaffee and Lemert (pp. 126-127) declared that in social science, "the first serious structuralism of the modern area was Karl Marx's theory of commodity values" and that he "understood that there was a structural scandal at work in the modern world": "Why is it that "the worker becomes all the poorer the more wealth he produces'?. They noted that Marx and Engels had already outlined the answer through a "basic structural principle" in the opening line of the Manifesto of the Communist Party (1848): "The history of all hitherto existing society is the history of class struggles"; Through that sentence, Marx and Engels "identified the scandal of modern industrial society which professed values of human values and progress while, under the surface of a liberal ideology, the capitalist class was as ruthless in its exploitation of the worker as feudal lords were of the peasantry". Going back in time, Chaffee and Lemert located in Marx's 1844 essay Estranged Labour his structural analysis allowing the first identification of the scandal: "that the estrangement (or alienation) of the worker begins in the factory system of production (the tools and resources owned and supplied by the capitalist 
class) and thus is cut off from the value produced by his labor (or labor power)." Looking for profit in order to accumulate capital at the expenses of the worker, the capitalist forces the worker to avoid unemployment by accepting structural changes such as the prolongation of the working day and the suppression of rates of pay. It is a structural approach that enabled Marx to link the physically smallest structure at the bottom, the commodity, to the covering and piloting structure at the top, the market.

The structural analysis that we propose to link the referential spoken/written word to reasoning presents some similarity to the one linking the commodity to the capital market and explaining the capitalist mode of production. Both structural analyses operate by identifying the structure at which a radical difference is produced. In the capitalist process, it is the surplus value engendered by the surplus labour of the worker. For the capitalist, it is the difference between the amount raised through the sale of the product and the amount it costed to the owner of that product to manufacture it (including the workers' salaries). In the process of human thought improvement, it is the difference between two types of thought, the one based on orality and the one based on writing. Literacy transforms oral thinking into literate thinking, and the return in this case is multiform: to give permanency to the constituents and the products of thinking; to augment the quantity, quality and degree of precision of the informational representations to be processed; to transform images into concepts; and, given all those improvements, to create a new cognitive capacity, metacognition, and different forms of conscious rulebased reasoning.

\section{Critical literacy in science and ideology}

Critical literacy should not be only critical of literacy products, it must be also critical of itself. Most of the people who are literates and skilled literate thinkers and reasoners do not think they are thinking and reasoning with concepts and lots of words that are literate, developed and consolidated through literacy. They do not notice this because they do not have the impression of seeing written words when they think. As a matter of fact, most of our literate processing is subconscious, even when we read, a bit more conscious when we write. We say this now because many scientists may feel outraged if they read, and indeed we are going to write, that science is scientific literacy. Yet this cannot but be accepted if we agree that science would not have been created in the absence of literacy. Before literacy, people learned many operational abilities, how to get some effects and why to avoid others. We do this when we cook, for example, but we do not call it science. Science is understanding of processes that are not accessible to our senses: science is needed for example to understand why the moon looks larger near the horizon than it does higher up in the sky.

Science is not myth, but many ideas admitted as scientific may later be proved to be mythical. Science is not a static "object". As science is scientific literacy, in the same way as literacy it is both permanently available and under continuous transformation. However, science is not always science, and this is a reasonable idea, given that was found to be a "scientific truth" can be put into question if not dismissed. The boundaries between science and ideology are difficult to trace, and it is this distinction that we are now going to address.

Knowing it is a risky task, we will start by a historical conceptual analysis. When the term ideology was created in 1796 by Destutt de Tracy, it referred to what the etymology of the word indicates: the science of ideas, or the science (idea) of knowledge (logos), i.e., in our time, cognitive science. According to Tracy, a new name was necessary "because "metaphysics" was too discredited, and "psychology" implied a knowledge of the soul which no one could any longer claim to have" (Kennedy 1979). Tracy outlined for investigation "ideological phenomena", including "unconscious intellectual habits, the "liaison' or association of ideas, particularly in language" (ibid., p. 354).

In fact, ideology "was a political and social ideology as well (...), the ideology of a group of propertied intellectuals in power after Thermidor" (ibid., p. 358). The institute created by the Idéologues has been coined College of Atheists by its opponents, who contributed to politicize it much more. The most famous of them was Napoleon, who was against individual liberties, in particular free thought and expression in the media. "This not ideology, but a real conspiracy", he told Fouché, Minister of Police during the Consulat and the Empire and who had been the greatest enemy of Robespierre (from Lecestre, cited by Kennedy 1979, p. 359). "They are dreamers and 
dangerous dreamers; they are all disguised materialists and not too disguised. (They) destroy all illusions, and the age of illusions is for individuals as for peoples the age of happiness." (from Talleyrand, ibid., p. 359). Since the coup d'état of October 1812, following which many idéologues entered the government and until he lost power less than two years later, Napoleon constantly denounced them: "who was it that proclaimed the principle of insurrection to be a duty? Who adulated the people and attributed to it a sovereignty it was incapable of exercising? Who destroyed respect for and the sanctity of laws by describing them, not as sacred principles of justice, but only as the will of an assembly composed of men ignorant of civil, criminal, administrative, political, and military law?" (speech before the State Council on Dec. 1812, ibid., p. 360).

Tracy and the Idéologie also had passionate admirers (cf. Kennedy 1979, pp. 361-362), among whom Stendhal, who confessed that Tracy's Ideology effected "an astonishing change in all my ideas" (Correspondance). Stendhal wrote in his De l'Amour, from the eponymous Tracy's book: "If Ideology is a detailed description of the ideas and all the parts which may compose them, the present (work) is a detailed and minute description of all the sentiments which compose the passion called loved..." In his correspondence with John Adams, Thomas Jefferson explained: "Tracy comprehends, under the word "Ideology", all the subjects the French term Morale as the correlative to Physique. His work on Logic, government, political economy and morality, he considers as making up the circle of ideological subjects."

The original meaning of idéologie is lost today, and few people know the importance it had. According to Kennedy (1979, pp. 363-368), it began to be used with the strict meaning of political ideology in 1812. Marx read and cited at least the fourth volume of Tracy's Eléments d'idéologie. Kennedy synthesizes quite clearly the fundaments of Tracy's political economy: “(...) you and me is the prior distinction, and yours and mine derive from it. Personality derives from the self, and property and wealth from personality. (...) Property is therefore "the inevitable consequence of our nature". The natural inequalities in men's faculties lead to the inequalities in distribution of wealth and consequently to the swelling of the ranks of the poor. (...) Private property is natural and its abolition, Tracy stated, would lead only to an equality of misery." Which implies: "Social conflict is not seen as class conflict, but as part of the universal struggle, the movement of individual wills in conflict with other wills. All men are capitalists since the worker must clothe and feed himself with the fruit of previous labour (Tracy's definition of capital) before going to work". In Das Kapital, Marx denounced Tracy's assertion that only the capitalist is truly productive ("Industrial entrepreneurs are really the heart of the body politic and their capital is the blood"), his identification of all particular interests with the general interest, and his "ideological defense" of private property, which led Marx to call Tracy a fischblütige Bourgeoisdoktrinär, a fishblooded bourgeois doctrinaire. Interestingly, Tracy's bourgeoise economic theory did match neither his "political ideology" typical of liberal nobility nor his real economic situation, as he was a rich landowner of thousands of hectares.

Marx did not care of Tracy's meaning of ideology, but used this term in a new sense, consistent with his views on political economy and social science, both integrating an historical perspective. Since property exists, human history is marked by a struggle between those who have the property of the material (or even human) means of production and those who do not have but want to get it. The developmental changes in production and production means may have put some of the until then non-proprietary in conditions to aspire becoming proprietary, through wars or other conflicts, at least of the most rewarding production means and the consequent goods. Drucker (1972, p. 154) explains that Marx refers to ideology in a double sense, as it depends on the position of a class regarding the property: “(...) when he refers to the thinking characteristic of an ascendant class-specifically of the bourgeois before they seized power-he is talking about something very different from the thinking characteristic of a ruling class-specifically of the bourgeois once they were in power."

This is obvious. In both cases, it is the thinking of a class, but depending on whether it aspires to property or has already taken it, its ideology is different. Ideology must be consistent, in one case, with aspiring to property (it tends to be "liberating", because the aim is to deprive the possessor) and, in the other case, with grabbing and profiting from property (it must be presented as the best and anyway only possible vision 
of the society). When the bourgeoisie was the ascendant class (it was the time of Adam Smith) it was great to lift restrictions on trade, then on workers' contracting (and, in the Lockean writings, slaves' property); but, when the capitalists became the privileged and powerful class, it is claimed that it is the best way to produce wealth and that the distribution of it will be as fair as possible while avoiding the global collapse, given in particular the fact that there is an increasing number of people to feed, care, educate and give jobs. In both epochs, the ideologists spoke in name of the same class, but, given the aims, historically different, the ideologies were also different.

There may be, however, a paradox in the Marxian conception of ideology. On the one hand, the ideology of the dominant class expanded largely around this class, and, on the other hand, the dominated class is fragmented into many sub-classes according to their social status and role in the capitalist mode of production, so that they do not have a common ideology. We clarify the two parts of the issue. The ideology of the rich and powerful class, which immorality grows with the fact that it is not showing signs of decline (no "French" revolution foreseen in the immediate future), is an ideology in the pejorative sense. Although that class is a very small minority of humanity, its ideology is shared by those who believe to be able to integrate it, and this is the case of large portions of the middle class, seduced by the ideas of competition and merit and the illusion that by developing "human capital" they will become capitalists or, at the very least, operational "brains" of capitalism. On the opposite side, the fragmented subclasses are ideologically dispersed into, as referred, those who share the capitalist ideology, those who look for a mere improvement of their situation, those who just attempt to survive, and, finally, those who, contrary to what is described in the Marxian theory, do not aim to be the ascending class but rather the class assortment erasing class distinctions. There is still no indication that what would be an ideology corresponding to this aim has gained influence. Which is, at the same time, the reflection of the present weak development of social critical literacy.
Conclusion: The necessity of a critical literacy of critical literacies

Above, we illustrated two manifestations of critical literacy in three domains or issues of human sciences: education, social theory, and science vs. ideology. There is a large variety of critical literacies depending on aims, contents, epistemic exigence, and their history and relations among them. Critical literacies are not a collection, rather a network requiring a thorough comparative analysis, which can only be done by a large corpus of collaborative experts. In the next, second part of the present paper, we will attempt to show how thinking, fertilized by literacy, engendered reasoning.

\section{From thinking to reasoning}

Many cognitive scientists working on reasoning make no distinction between thinking and reasoning. We consider that thinking is a general term and reasoning a particular kind of thinking. If we say, for example, "We don't have any meat" we are thinking but we are not reasoning. If we think "We don't have anything to eat. Tomorrow we will need to hunt a big deer", it could be, but is not necessarily, a mental act of reasoning, because the relation between the two thoughts may be due to the high frequency of the occurrence of a sensation (hunger) and an image (the deer). Reasoning consists of establishing explicitly an inferential relation between two propositions consistent with "Given $\mathrm{x}$, then $\mathrm{y}$ ".

Thus, in their simplest and most common definitions, thinking, or thought, is any deliberate or undeliberate associative flow of either ideas or images or both; whereas reasoning is applying logical principles, with conscious knowledge or not, on sets of propositions to derive, from these, inferences that are taken as new knowledge or as motivation for action.

Before addressing rationality and reasoning more specifically, which we will propose to be literacydependent, we begin by addressing thinking. Humans, at least since some age and whatever their degree of literacy, are recognized as subjects of thinking, even if both age and literacy contribute to the development of thinking. We will discuss what is or should be called thinking, to what extent it depends on literacy, and 
who can be a thinker, i.e., subject of thinking. We will argue that the three issues are in fact interrelated.

Thinking viewed from a human and literate perspective

We realize, at the moment of writing this, that we could have interviewed illiterate people on what they think thinking is and asking them also for examples of thoughts. Too bad. We will do it, this way we can now offer a public prediction, namely that illiterates, like medium-level literates, would be quite familiar with the words thinking and thought (the noun), and that they would give appropriate examples of both. Asked to point where they have the thoughts, they would indicate the front of the head. And if asked about reasoning rather than thinking, they would probably give the same kind of answers, nothing resembling argumentation with premises and inferences although we know, from informal verbal exchanges, that when appropriate and useful they can argue and give explanations.

The traditional literate perspective of silent thinking is that it is a human capacity not shared with other animals, certainly not with plants, and that its medium is language, inner speech. However, people who work with animals or with frequent contacts with them and/ or have pets may attribute them some thinking. To the others, the common idea is that animals do not think because they do not have language, that the sounds they produce cannot support thinking, and that when they can repeat human speech, as in the case of parrots, it is purely mechanical. This idea has been conveyed by Descartes, supported by many philosophers, and began to be contested only with Darwin and some philosophers by the end of the twentieth century. Below we will evoke this change very briefly, after answering the question: how could the humans, in particular the human elites, have been so sure, and for so long, that only humans think? The reason is similar to the one that induces everybody, and especially most linguists and cognitive scientists, to be absolutely sure that the human linguistic and cognitive capacities are the product of genetic mutations, biologically transmitted since then without any major influence of sociocultural factors, namely factors linked to and resulting from the collective human praxis. Since the advent of the social classes, the rich and powerful people, and the intellectuals (scientists, ideologues) who surround them, in a single word, more or less the literate generations of the last five thousand years, were self-persuaded that what makes humans special is their patrimonial and biological inheritance, insuring for the elites the perpetually renewed inheritance of both wealth and intelligence, now designated, respectively, by capital and IQ.

The dominant culture and ideology are those of the dominant classes, and as the humans became the dominant animal, they (more exactly, the dominant groups among the humans) decided that they were biologically and cognitively unique and superior to all the other animal species. As they have language, they decided that the other species do not have any, which was quite obvious, given that, even if these had some language, the humans could not understand it, so the other animal's forms of communication were not languages. And, not having language, the other animals could not think. True or false, the humans and their leaders (in power or science) learned to dominate the world in all its aspects and to subordinate to themselves all the other animals, to the point of sometimes forgetting they are also animals.

Could thinking be the privilege of humans? It seems that even plants do "think": association learning by seedlings of the garden pea may guide foraging behavior and ensure survival (Gagliano 2017). However, it is for the non-human animals that the question has since long been considered, in particular by the philosophers. The US philosopher and well-known professor at Berkeley Donald Davidson (1982, p. 319) said to have often given talks under the title "Why animals can't think" (note that, in this proposition, though not explicitly, the humans are not presented as an instance of the "animal" concept). He immediately stated that "only creatures with a language can think", thus excluding, for example, the possibility of thinking by associating images. He added "to believe (...) that men and women are alone in having language, or enough language to justify attributing thoughts to them." He recognized that "the view that thoughtbelief, desire, intention, and the like-requires language is controversial, but certainly not new" (p. 322), but clearly stated: "My thesis (...) is that a creature cannot have a thought unless it has language. His argument, however, is undermined by a lack of differentiation between though and reason: "In order to be a thinking, rational creature, the creature must be able to express many thoughts, and above all, be able 
to interpret the speech and thoughts of others" (pp. 322-323).

Actually, Davidson made two amalgams: of thoughts and reasons, and of language and speech, and argued (1) that "in order to have a belief, it is necessary to have the concept of belief", what he considers to be "a belief about a belief" (cf. p. 326) (as if to love or to know one would need to have the respective concepts), and (2) that "in order to have the concept of belief one must have language". Davidson further argues that, for example, "be surprised", is to gain awareness of something unexpected and this implies a belief about a belief. The example he gives is that, if a dog ceases to see a cat that went up an oak tree, the dog cannot feel surprised for the simple reason that a dog cannot have beliefs about beliefs. It would imply the dog to have the concept of objective truth, "the idea of an objective reality which is independent of my belief" (p. 326), in this case the dog's belief on the existence of the cat he ceased to see. Linguistic communication would be necessary to the "concept of an intersubjective world" which is "the concept of an objective world" (p. 327). We described this philosophical belief about the absence of thinking in dogs and other non-human animals in part to refer to the disbelief on other animals' thinking but also to show that sometimes literate thinking and reasoning may lead to absurd inferences.

Other philosophers of the same period have addressed the question of whether thinking is common to or, instead, divides human and non-human animals. Examining the question of animal awareness, Donald Griffin (1976) wrote that "mental experiences, like other attributes of animals and men, exhibit a continuity of variation and are not typically discrete, all-ornothing qualities totally restricted to a single species." (p. 68). Griffin cited a neuroscientist of behaviorist orientation, Lashley (1959), who adopted the same principle: "A comparative study of animals is a comparative study of mind, by any meaningful definition of the term".

Another philosopher, Gareth Matthews (1978, p. 437), expressed clearly that "the psychology of human beings is part of the psychology of animals generally" (p. 437). He believed that "there are always psychological continuities, never any strict discontinuity." (437) and exemplified it as follows: "Suppose attentiveness is a psychological state to be found in human beings. Then, according to the Principle of
Psychological Continuity, there is an animal of some lower species, say a rabbit, such that the rabbit is capable of a psychological state that is a model of attentiveness in human beings"; or, "suppose the projection of one's anxieties on someone or something is a psychological function to be found in people, or perhaps in chimps, then, according to the Principle of Psychological Continuity there is an animal of some lower species, say a dog, such that there is a psychological function in the dog that models anxiety projection in chimps or human beings" (p. 438). He mentioned Donald Hebb (1946) who, by observation, ascribed to non-human animals emotional and psychological attitudes similar to those of humans, in a way allowing the staff of the Yerkes Laboratory of Primate Biology to agree among them on whether, toward the human being, one animal was fearful, nervous, shy, friendly, or hated him.

Interestingly, among the more ancient philosophers, Plato and Aristotle had reunited the humans and the other animals in conformity with the Principle of Psychological Continuity. To Plato (Phaedo and Timaeus), due to metempsychosis, or transmigration of psyches, your psyche might next animate a dog or a fish. To Aristotle (De Anima), there are three kinds of psyches: plant or nutritive souls; animal or sensitive souls; and human or rational souls, each psyche incorporating the function(s) of the previous one(s), and so he also assumed a radical discontinuity, as in non-human animals there would be nothing similar to human reason (Matthews 1978, p. 439); and the corresponding qualities would differ only quantitatively: "just as in man we find knowledge, wisdom and sagacity, so in certain animals there exits some other natural potentiality akin to these" (p. 440).

The Principle of Psychological Continuity had been broken by Descartes, who assumed that among animals only the humans have minds and, given that only those who have minds are conscious, the humans are conscious whereas the non-human animals are automates, their 'psychology' is the "psychology of brutes'. He asserted that (XXX), the "chief essence of man (applies) only to the principle by which we think, (...) I have called by the name of mind": "I consider the mind not as part of the soul but as the whole of that soul which thinks." So, non-human animals may have a soul or a psyche (non-conscious, mechanical), and the humans are the only animals that have a mind, i.e. that think. Mind? We must say that, four centuries 
after Descartes it is time to accept that there is no mind, nor "esprit". Mind is just a literate concept (a pleonasm, as all concepts are literacy products), a "substantif" (noun) that actually designates an individual changing pattern of mental events or thoughts, the thoughts being the outputs of thinking.

Thus, as Matthews (1978) said, Descartes rejected the Principle of Psychological Continuity, accepting only a principle of behavioral continuity. Writing to the Marquess of Newcastle in 1646, he said that "when the swallow come in Spring, they operate like clocks. The actions of honey-bees are of the same nature, and the discipline of cranes in flight, and of apes fighting ..." (p. 453). The major difference, to Descartes, was not between living and non-living, but between the minded and the mindless, namely the humans and everything else. Matthews insisted on "Descartes' (1649) reiterated appeal to speech as 'the only certain sign of thought hidden in a body', and on "Descartes' confidence that only human animals are capable of consciousness rests ultimately on the idea that only human beings are capable of doubting propositions and hence only human animals are capable of a selftransparent 'inner' or mental life." Matthews objects this arguing that "at least some non-human animals are capable of suffering pain. (...) If their pain states were not genuine mental states, but only mechanical ones, as Descartes suppose, it would always be inappropriate to feel compassion for the sufferings of non-human animals. But it is not always inappropriate". Indeed, "such animals lack (...) the capacity to doubt propositions", but then this capacity "is not a prerequisite for having a genuine mental life" (p. 454).

Concerning Descartes, Matthews also mentioned an interpretation of the French philosopher that Norman Malcom offered in his American Philosophical Association presidential address, "Thoughtless Brutes” (Malcom 1977). Malcom (pp. 54-55) wrote: "The relationships between language and thought must be (...) so close that it is really senseless to conjecture that people may not have thoughts, and also really senseless to conjecture that animals may have thoughts." So, to accept that "animals do not have thoughts", says Matthews, Malcom (p. 56) draws a gentle distinction between thinking that $p$ and having the thought that $p$, so that non-human animals can do the former but not the latter, and suggested: "Descartes mistakenly equates thinking with having thoughts. His view is that 'a mind' is something that has thoughts. (...) I have thoughts, but my poor doggy has none. So I am a mind, but he is not." However, Malcom had said above (pp. 47-49): "In my opinion this is an absurdly overintellectualized view of the life of man. It helps us to understand, however, why Descartes thought that animals are automatons. They are devoid of mind, (...), because they do not 'apprehend', 'entertain', 'contemplate', or, in plain language, think of propositions." Matthews' remark on it: "This is, I believe, an apt comment on Descartes" (p. 449).

Still, we think this discussion has not touched the heart of the problem: the non-equivalence of the mental process and of the ("overintellectualized", i.e. literate) reified process output. While feeling and thinking designate multidimensional (physiological, neural and mental) processes, their first level reified outputs (i.e. their transformation into things) are the nouns "sensation" and "thought". These nouns, like the verbal forms, belong to the language that we, humans, use in both outer (speaking) and inner (thinking) forms of expression of our thoughts. Together, literacy and abstract thinking must have contributed to create concepts to nominalize and identify the origin of thoughts. The brain has since long been considered as the locus of the thinking activity and therefore of its outcomes, the thoughts. However, it also seems that the humans felt the necessity of attributing them to an instance that would not be physical but of the same nature as the thoughts. Nobody made a serious inquiry into it, but it is quite possible that most people today persist in believing that, although the thoughts are created in the brain, this happens through or by means of a spiritual or mental entity/device the philosophers and the psychologists call mind.

If Descartes substantialized mental processes by admitting, in human beings and only them, a mind paired to, or within a body, the concept of mind remained, and the word is still used frequently. Concepts are quite useful and facilitate reasoning, including in science, but, precisely because they are literate constructs, they must be the object of a particular form of critical literacy, the critique of the literacy products. The XXI century philosophy is still discussing the nature of mind. 


\section{More on the non-human animal thinking}

Wittgenstein's claim "If a lion could talk, we could not understand him" has been used by Beck (2013, p. 520) to introduce his paper entitled "Why we can't say what animals think". Whether such claims are true or not depends on whom "we" are. If Wittgenstein and Beck have known lions as well as we know them, those claims are true. But we would not say the same if instead of a lion the above sentences concerned Perle (Pearl), our 16-year old white persian cat. She doesn't really talk, but we understand her quite well and are convinced she understands us. And it should be true also between a lion and the people in charge of "him"-incidentally, was the human pronoun an innocent mistake?

Stewart (2009) agreed with Davidson (1982) belief that no creature without a language could be an intentional agent. Stewart specifies that this "concept of an agent is part of the matched set which constitutes propositional attitude psychology-that it is a precondition, indeed, of any non-metaphorical use of concepts like belief, desire and intention." (p. 218). Referring to ideas put forward by child developmental psychologists, she concedes, however, that "the concept of agency is a more basic possession than some of the propositional attitude concepts proper", and so "there may be room for us both to accept what seems to me to be the extremely natural view that large numbers of animals are agents, and yet to concede, along with Davidson, that they may perhaps not have any states which would be truly appropriate to call "beliefs" (p. 219). Beliefs imply thinking, and this is unacceptable: non-human animals do not think. Thought requires language, a propositional attitude, for example a verb governing a "that" clause: "I, Perle, believe that you are preparing my lunch". Hence, Perle cannot have such a belief. In other words, only animals possessing propositional language have beliefs. Stewart did not make any step forward to admit that non-human animals have a mental life.

If we want, for example, to understand children's capacities, we should beforehand have a personal and close experience of children. This also applies to nonhuman animals. Vinciane Despret (2008) made an inquiry among cow and pig breeders who have an everyday practice of these animals. She wrote that the breeders and their animals "have a mutual knowledge and take seriously what breeding means: 'we don't stop talking with other animals'." (p. 124). She also mentioned the philosopher and dog and horse trainer Vicky Hearne (1994, pp. 3 and 168) who (1) reacted to Wittgenstein's famous sentence: "What does he mean? That if my lion Sudan started talking to me, we would stop being able to understand each other?", and (2) commented that philosophers find themselves "astray by a habit common to all talking parrots: their refusal to let another individual choose the topic of conversation.". To Despret (pp. 124-125), "no parrot has ever spoken to a behaviorist (because) they deduce that if they spoke, nobody in that situation would hear them. (...) parrots have a pragmatical rather than a referential conception of language. They cannot speak if they don't feel they are speaking to someone. And this someone is cruelly lacking in the behaviorist apparatus." It seems a joke but is more than that: for birds, "language must be learned/taught in its pragmatic function: it is an effective means of acting and of making others act." (p. 125). Alex, a gray parrot from Gabon, studied by Pepperberg (1995), not only could "speak, describe, count, classify objects in abstract categories, and use concepts like "same" and "different", but was also able to use speech so as to influence the behavior of others: "I want to go that place", "no", "I want this". By restating and inverting the question of control (...) the laboratory authorized a superb exchange of properties between the researchers and their subject." (Despret, pp. 125-6). Which explains the parrot's silence in the behaviorist lab. There, the parrot, like a political prisoner, refuses to talk and be dominated by the Man. Despret (p. 127) repeated the question Pepperberg posed "at the end of her work with the parrot: what does Alex really authorize me to say about parrots? I cannot, she says, affirm that all parrots talk (...). Alex is not representative of parrots; no parrot could be". In the same vein, Despret says that "we will know nothing about lions if we follow Wittgenstein and Dennett (who commented on Wittgenstein's sentence) because the latter are evidently not pertinent spokesmen for lions (...). The question is not what is a lion, but "how does one become a lion", not only in the lion community, not only in the lion's species, but also (...) in the work of scientists constructing what is to be a lion. This is a question of becoming: of that of which the animal is rendered capable by the apparatus that interrogate it, by the narratives that guide these apparatuses, by the hours of work spent observing them" (ibid.). Coming 
back to Alex: "Alex talks because Pepperberg desires it and demands it of him, and because she was able to subordinate her desire to what makes sense for Alex in the matter of speaking. (...) Alex talks because for diverse reasons his desire overlaps with that of Pepperberg" (p. 127).

We mentioned that Despret (2008) worked with breeders. To her, "the breeding apparatus (...) creates subjectivities. (...) in the best farms, talk is incessant. And because there is talk, there is talking back" ( $p$. 133). It is illustrative listening to one of the breeders: "it was winter, we came back at 7-30 in the evening. Someone calls us saying "you have a cow in difficulty (...)". I set out with the torch. The cows were spread out over 13 hectares. (...) Suddenly I hear the noise of hooves. The herd had detected me, the entire herd. (...) I talk so they recognize me. I see them turn around and go off. And I say to them, joking 'don't you want to help me for look for Semba?' And they have taken me to the cow. They have all made a semi-circle around us along the fence. They've waited there and they've taken me to the cow, who had, effectively, given birth. She couldn't get up anymore. They knew why I had come and I think maybe that they must have known I could do something for her." To Despret, "Language (...) 'populates' each of the beings present with perspectival propositions. (...) propositions of intentionalities. One gives words like one ascribes intentions. This practice, which inscribes the animal in the world of 'speaking' (...) works to blur the frontiers between humans and animals. (...) Breeders are perspectivists: each perspective is made up of a translation of intentions." (...) we find this trait again in nearly all the breeders questioned: they attribute to animals the capacity to attribute intentions to their breeder. (italics in the text)—we heard it many times-'animals know what we want better than we know what they want'" (p. 134). One of the interviewed breeders subordinated the question of differences to that of expectations: "what do we expect from animals?', and resumed: "I'm not sure that an industrial farmer expects the same thing from animals as a small holdings farmer, who has a different approach in the sense that he considers that he must be in harmony with nature, whilst the former has instead to adapt nature to his requirements" (p. 136). One may conclude with this Despret's proposition (p. 135): “ This extension of subjectivities, which breeding situations activate quite faithfully, resembles what can be called intersubjectivity: becoming what the other suggests to you, accepting a proposal of subjectivity, acting in the manner in which the other addresses you, actualizing and verifying this proposal, in the sense of rendering it true".

Jumping briefly to a socioeconomic perspective: “(...) all creatures have been turned into property. The creatures, too, must become free." This was claimed by Thomas Münzer, the leader of the German Peasant's revolt in the early sixteenth century and was recalled by Marx in On the Jewish Question, and again by Lawrence Wilde (2000), whose purpose was to refute the idea that Marx lacked respect for animals. He added that shortly after endorsing Münzer's sentiments, Marx characterises his own brand of communism as the equation of humanism and naturalism. We will not develop this issue here, beyond saying that, to Wilde, Marx "argues that it may be possible to define human uniqueness by such things as consciousness or religion or 'anything else you like', but humans really begin to distinguish themselves from other animals when they begin to produce their means of subsistence. (...) and views human essence as creative social activity" (p. 39, Marx's expressions within commas).

\section{Thinking uniquely human?}

Thinking is undoubtedly present in non-human animals, as evidenced in great apes (Osvath and MartinOrdas 2014), corvids (Taylor 2014), dolphins (Herzing and Johnson 2015) and domestic pigs (Marino and Colvin 2015), for instance. A culturally evolutive account of thinking distinguishing uniquely human thinking from thinking shared with other animals has been proposed by Tomasello (2014). To him, the thinking processes that are unique of humans are "objective" (represented independently of conflicting perspectives), "self- and socially reflected" (inferences from the others and the self), and normative ('reasons" resulting from experience evaluation). The non-human thinking shared with other animals would be intentional but individual, self-monitored and selfinstrumental. One may note, however, that the cows' behaviour described by Despret (2008) does not conform to that criteria. Moreover, Tomasello observed that great apes can cooperate when their personal satisfaction requires transitory cooperation with the others. To Tomasello, shared intentionality is 
unique to humans, being "joint" (between the interactants, one or some more partners) in a first stage and "collective" later on. However, collective intentionality only occurred within the same group or tribe. Additionally, it seems that in the last 10 or 12 thousand years it was rather "divisive intentionality", and nowadays it is intentionality "of the few against the mass", so we retrograded to "joint" intentionality. Tomasello recognizes this last change as he distinguishes the "we" and the "them" identities. The shift from the self to the several or more may have been enough to develop a shared or common intentionality, with the advantage of decentring from the individual the mental representation involved in thinking, but this may have occurred in some non-human animals. We believe that the development of communication systems, first through the primitive forms of language, signs, icons and gestures, then by vocalizations and later through speech, has been crucial to reach the unique human thinking, which, more recently, was and remains influenced by literacy and the scientific and technological accomplishments that took profit from literacy. What is unique in our human thinking remains to be identified more precisely. In the meanwhile, reasoning, the conscious analysis-largely influenced by literacy - of the processes through which one derives conclusions from the combination of thoughts, is, obviously, unique to the human animals and to the thinking and reasoning machines they created.

Such "clever" machines, above our capacity, should not move us. After all, they were created by the humans, who also invented the microscope and the telescope to see what their eyes could not perceive. We cannot "see" why thinking is more special than seeing. The thinking and reasoning of the intelligent machines will lack, for at least a long time, a capacity that many animals, human or not, do have. It was illustrated in a philosophical drama ChatBot le Robot, written in French by the Belgian philosopher Pascal Chabot. This is a form, among others, of addressing cognitive science issues that, unfortunately, the literate elites are forgetting after having practiced it in the past.

ChatBot had been taught philosophy to be later questioned by a jury of human philosophers who should decide if "he", ChatBot, is really a philosopher. He learned the concepts of the Western thinking, in the dictionaries, obviously also in The Oxford
Dictionary of Philosophy and the German, American, etc., reference books, millions and millions of papers published in savant journals. In other words, ChatBot is not human, but he is literate, and a critical literate. Nobody, before him, had acquired such a huge amount of knowledge and of argumentative schemas. He worked on those texts, received feedback from human philosophers, became like a philosopher among the philosophers, or the one who condensed all the philosophers, except that he had never confronted with the question "what is a robot?". The five questions he has now to answer the jury are: (1) May a robot be a philosopher? Isn't it a contradiction? (2) Do you exist? How do you define yourself? (3) What is self-consciousness for a robot philosopher? (4) Can the robots be better than the humans? Unexpectdly, the fifth question is replaced by a harsh dialogue on doubt and death between the robot and the highly critical Barnabooth with whom he already had several harsh exchanges: " $B$. took a chair and came near the machine: '- It's easier to talk, said B. - Indeed. - Do you suffer? - Not at all. - I believed to perceive a vindictive tone in your answers. - It was not intentional. - Bitterness? - I don't think so. You asked me what my self-consciousness is. I thought it was interesting to inscribe it in a power balance....' And it pursued taking a route that was becoming dangerous for ChatBot. B: '- Maybe you can teach us not do die. Or to doubt differently. - Perhaps. - And of what would you doubt. The robot took some time to think: 'I doubt of you.' Follows a long, open and sincere ChatBot's speech, after which B. tells him that after the audition, ChatBot would probably be employed by a world corporation that would use his superintelligence to increase its dominance in the market. The exchange becomes more dramatic, in particular over the destiny of ChatBot, until this asks out of a tiny voice: 'Are you sure there is no place for me in your office? We might speculate freely about the possibility of non-violent ethics...' The tiny voice could be the signal that ChatBot is becoming human. Does thinking and reasoning fill a life without feeling? What is feasible: put feelings in the AI literate machine, or allow the sentient humans connect with AI when they are in the mood to? Any literate machine in itself is just semi-literate, because full, true literacy also involves feeling, emotion, blow, shock, awe and wonder. 
Is reasoning literacy-dependent?

Only a few studies have examined whether literacy might also have a distal effect on reasoning, and more generally on what is considered as "intelligence". Intelligence and thinking must have pre-existed literacy. But literacy and literate activities allowed us to develop methods and strategies of formal reasoning. Literacy was a necessary condition for the development of mental activities like philosophy, logic, and science. It must also help in "intelligence" and reasoning tests.

In agreement with this idea, Verhaeghe and Kolinsky (2006) found extremely low scores when they presented Portuguese illiterate adults with the first three series of the Raven's Progressive Matrices, which are tests of inductive reasoning. They performed at the percentile 50 for 7 years and-a-half schooled children. And the ex-illiterates were not better, perhaps because their reading abilities were too poor to be useful in such cognitive situations.

In Brazil, we presented illiterate, semi-literate and literate adults with a concrete, familiar version of the Wason's selection task, a test of deductive reasoning that requires verifying the accuracy of a conditional relation (Wason 1966). Instead of the letters and numbers used by Wason, we used for instance the photos of locally well-known athletes and their usual sports equipment, as for example a tennis racket for the (locally-born) tennis player Gustavo Kuerten (nicknamed "Guga"). Performance was very poor, but to half of the participants we offered corrective feedback and for them we found an immediate strong improvement in the literates, and delayed ones in the semi-literates and illiterates. One illiterate participant succeeded on the first trial and remained successful. He spent lots of time thinking, especially in the first trials. At the end, we interviewed him. He was completely unable to explain verbally how he reasoned. So, he had just a metalinguistic and metacognitive incapacity, due to the lack of literate thinking.

The most famous studies on the impact of literacy and/or schooling on reasoning used syllogistic reasoning. Luria (1976) reported that illiterates could not perceive the logical relation between the parts of the syllogism. Yet, this seems to reflect an empirical bias. Indeed, when presented with unfamiliar premises, illiterates use their own experience to supplement, distort, or even reject them. For example, when given the problem: "In the far North, where there is snow, all bears are white. Novaya Zemlya is in the far North. What color are the bears there?", an illiterate participant answered: "I don't know. I've seen a black bear. I've never seen any others... Each locality has its own animals" (Luria 1976, pp. 108-109). The notion that this reflects an empirical bias is supported by the facts that illiterate people are quite good with syllogisms based on familiar information (Scribner and Cole 1981) and that, with unfamiliar information, they reason accurately and appropriately justify their conclusions in terms of the supplied premises when explicitly prompted to think of these as pertaining for example to a distant planet, which allows them setting empirical considerations aside (Dias et al. 2005). Nevertheless, the illiterate participants of Dias et al. (2005) performed less well overall than the early literates.

Even literate schooled people struggle with syllogisms, especially when their beliefs enter into conflict with logic. More specifically, they tend to endorse arguments whose conclusions they believe and reject arguments whose conclusions they disbelieve, a belief bias which is modulated by logics, as it is more marked on syllogisms which conclusions are invalid than on valid ones (Evans et al. 1983). Recently, our research group has had the opportunity to examine the effects of belief and logic in 20 adult literacy students. These showed a weak effect of validity (tendency to accept more valid than invalid conclusions), which was positively correlated to reading, and a strong believe bias, which was negatively correlated to literacy measures. Thus, literacy seems to help reasoning in two ways: both directly, by improving logical thinking, and indirectly, by reducing the belief bias.

It is usual to distinguish between epistemic rationality and instrumental rationality, the former designating the conditions allowing to derive or consider some statement as knowledge, and the latter referring to the operational means that assist such a process. We agree on this. Yet, although some authors (e.g., Stanovich 2013) attribute instrumental rationality to numerous animals, such as insects, to guide their flight or exploit frequential distributions, we believe that some aspects of our rationality such as intentional and verbal or numerical logical inference, deductive, inductive and abductive reasoning, are specific to our species, precisely because our language, including 
literacy, support these cognitive capacities. It remains to be known, in much greater detail, to what extent and quality language, and literacy, impact them.

The argumentative theory of rationality

Besides pure cognitive theories of rationality, the argumentative theory of rationality developed by Sperber and Mercier (Sperber 2001; Mercier and Sperber 2011) explains it as a product of our living in society. The main idea is that reasoning evolved neither to allow isolated individuals to enhance their individual cognition, as proposed by the classical view of reasoning going back to Descartes and the ancient Greek philosophers, nor to deal with novelty and anticipate the future (Evans et al. 1996), but rather for arguing ones with the others, for producing and evaluating arguments. The aim is not to the truth, but to find arguments that will convince the others without being persuaded by them. Allowing communicators to argue for their claim and addressees to assess these arguments would increase both in quantity and in epistemic quality the information humans are able to share, therefore enhancing the effectiveness and reliability of communication. This would be crucial for cooperation.

We certainly agree with Sperber and Mercier on the notion that argumentation and counter-argumentation are very important. In their 2017's book the Enigma of Reason, Mercier and Sperber put great emphasis on communication, and we also agree with them (who would not?) on the idea that reasoning relies on language. Yet they refer only to oral language, and completely ignore the role of literacy in the development of reasoning through History. Amazingly, they take examples of interactive argumentation from putative oral exchanges between Sherlock Holmes and Dr. Watson, forgetting these were literate characters and that their exchanges had been written. And this despite the fact that when they recall that the invention of Aristotle ended up with "logical forms", they describe how it was done in the following way: "replacing concrete contents (...) with arbitrary symbols such as capital letters" (p. 36; italics are ours).

Mercier and Sperber (2017) do not fully ignore cultural evolution, as they mentioned Dehaene and colleagues' work showing that "the biologically evolved properties" of brain tissues are "recycled for a novel, culturally evolved function" (p. 75). What they seem to ignore is the interaction between cultural and biological evolution, and that culture impacts not only the neuronal functions and connectivity but also epigenetics. For Mercier and Sperber, "evolution" is only biological and driven by the genes. Although they acknowledge that "reason has obviously benefited from various cultural enhancements" (p. 3), they do not specify which cultural influences, and do not make explicit reference to literacy. They believe that reason is a biologically evolved universal trait. They argue that "skills such as reading or chess playing are still much too recent for something like a learning instinct to have evolved in order to help with their individual acquisition" (p. 72) and that "All normally developing humans can produce and evaluate arguments" ( $\mathrm{p}$. 281). It thus seems that, for them, typical development does not require formal education, so that illiterate unschooled people should be as able as literate schooled ones to produce and evaluate arguments.

Mercier and Sperber (2017) describe language used in argumentation as follows: "Several sentences can be embedded in a more complex sentence to articulate a reason" (p. 154), and "A number of so-called discourse markers, such as the connectives "so", "therefore", "although", "but", "even", and "however", have an argumentative function" (p. 155). They forget that these are precisely two specific characteristics of literate language, not or very seldom observed in preliterate language, according to the ethnologists.

Castelain et al. (2018, see also Mercier et al. 2014) observed that, before three years of age, children already exchange arguments with their parents, and are able in all cultures to distinguish strong arguments (e.g., "the dog went this way because I've seen him go in this direction") from weak ones (e.g., "the dog went this way because he went in this direction"). Yet, neither of these observations refutes the idea that the subsequent huge development of reasoning and argumentation is due to the interaction of literacy acquisition and practice with cognitive development.

Castelain (2014) commented that if reasoning results from a biological adaptation, these capacities should be relatively universal, and they should not need to be taught. The problem is that they need. As we will discuss at length in a further section, it is the idea that reasoning develops naturally according to the genes that led American psychologists by the time of the First World War to develop tests of intelligence 
that allowed the US Immigration service to declare that the immigrants from the North of Europe had IQs above 100 and those from the South IQs below 90. And it is education that explains, for example, the reasoning results obtained by the Chilean Grades 3 and 4 children examined by Gelerstein et al. (2016). These varied with grade but above all with sociocultural level, with average scores of 19.3, 10.7 and 7 for high, medium and low socioeconomic class, respectively, in Grade 3; and 22.2, 14.8 and 10.6, in Grade 4. Schooling helps (there was an average increase of 3.5 from Grades 3-4) but social class is the major determinant. The high socioeconomic class outperformed the medium class by an average difference of 8 , and the low class by a difference of 12 . Interestingly, standard deviations, as a proportion of the means, were much smaller in the high class $(0.18)$ than in the median (0.54) and the low (0.69) classes. Performances are thus much more homogeneous at the top of the socioeconomic range.

In addition, argumentation and counter-argumentation can be taught. Critical thinking in argumentative writing systematically improves more when students receive instruction on argumentation, counter-argumentation and rebuttal than on argumentation only (e.g., Liu and Stapleton 2014). The situations used did not involve any social antagonism. They just led the student to consider a topic from different and opposed perspectives.

Epistemic verification: the basic component of critical literacy

Let us take a cognitive look at what is critical literacy. Being a particular form of literacy, critical literacy must share with literacy the cognitive processes involved in the comprehension and production of both written language, which is made of propositionstructured texts, and of similarly structured spoken language, to the extent that this is influenced by literacy.

In terms of cognitive processes, critical literacy must, in principle, differ from literacy in two ways. One of them is epistemic verification and assessment (the other, the unescapable influence of axiological and ideological options, will be considered later). Epistemic verification is a controlled process enabling the receiver to identify the received information as epistemically true or false (in some cases, just inappropriate), and the producer to check the information for epistemic truth (or appropriateness) and modify or even suppress it if found to be incorrect or imprecise. We refer here to the crucial cognitive processes involved in critical literacy when there are substantial divergent views, expressed through language on epistemic, ethical or esthetical issues (and excluding personal ones, emotional or affective, or stylistic ones), among different people or groups of people.

A complex issue whose roots may be found in Descartes and Spinoza is to understand the temporal relations between, on the one hand, the comprehension of a statement that we read or listen for the first time and, on the other hand, its epistemic verification. The opposite views of those philosophers on this issue of belief fixation and the history of this debate were described by Gilbert (1991), who synthesized the main views as two opposite responses to the following question: "Is there a difference between believing and merely understanding an idea?" (see also further discussion in Mandelbaum 2014).

For Descartes the answer was yes: we comprehend the meaning of the statement, and only after, through confrontation with our knowledge or beliefs, we verify if it is true (and believe it) or not (in which case we reject it). In contrast, for Spinoza, in the first stage, comprehension includes acceptance, more exactly comprehension is already belief; and in a second stage we may or not verify it, which possibly leads to disbelieve it.

In fact, Descartes and Spinoza insisted on different concepts. Descartes, who attributed a major to the concepts of "doubt" and "truth", claimed that one is not entitled to assume something as true whenever a slight chance of doubting remains. Assuming truth should only intervene after reasoning and, from such an assumption, it would not follow indubitability. To Descartes, truth refers not so much to the correspondence between thought and reality than to the coherence between the outcomes of reasoning. In Meditationes de Prima Philosophia, he advised chasing preconceived opinions and his method consisted of suspending as much as possible all beliefs. To have reasons to doubt, it was necessary to consider the possible skeptical scenarios. He believed this suspension of belief can occur effortlessly, with a simple act of will, and the only difficulty would be to overthrow a precocious decision of believing. Indeed, Descartes 
cautioned us that, in case "we have resolved not to assert or deny anything, we easily forget our resolution if we have not strongly impressed it on our memory". Quite differently, to Spinoza, "idea" and "belief" are the important concepts. Ideas do not refer to the objective reality, but to the products of thought, so that there is no major difference between having an idea and believing it. Beliefs are the most powerful ideas, after evicting poor ones, they are representations for actions. Spinoza reversed our subjective notion of intellect and will, by considering also their relations with affectivity and passion. We do not begin by taking things as existing and then are affected by them. It is the reverse. It is what we do and the way we are affected by things that make us take them as existing and form our ideas of them, which above all are representations and reasons for action. Ideas may be more or less adequate. Forming an adequate idea of a passion becomes a powerful reason for action. Scientists and others can recognize this process which is not circular but helicoidal. To Spinoza, misperceptions were neither beliefs nor errors. For example, to see the sun near us (a non-existing thing) is not an error, it is just due to lack of knowledge. If someone has never been led to think about the deceptiveness of the senses, he will never doubt whether the sun is larger or smaller than it appears to be. Questioning and investigating are necessary to gaining understanding. To illustrate this, Spinoza commented that people who does not think about the deceptiveness of the senses are surprised when they hear that the sun is much larger than the earth. According to Israel (2001, p. 242, cited by Buyse 2017, p. 104), "Spinoza spent much time experimenting, studying experiments, and discussing experimental results with scientists, as well as assembling microscopes and telescopes". "Still more, (...) it was basic to his conception of his philosophy that his thought should be anchored in the rules and procedures of mathematics and science".

After Descartes and Spinoza, many distinguished philosophers and psychologists worked and wrote about the relations between comprehension and assessment, or-said somewhat differently_between understanding and believing. According to Gilbert (1991), Alexander Bain, in 1859, contrasted the "primitive credulity" of human beings with their "acquired skepticism", commenting that "we begin by believing everything; whatever is, is true". He also noted that Bertrand Russell, in The Analysis of Mind
(1921), reticent about the Spinozan hypothesis, nevertheless declared it in accordance with mental development. On this matter, Gilbert remind us that "the ability to deny propositions is one of the last linguistic abilities to emerge in childhood".

In spite of their different views, Descartes and Spinoza both assumed two processing stages. To Descartes, first we comprehend, then we verify; to Spinoza, in the first stage, comprehension includes acceptance, more exactly comprehension is already belief; and in a second stage we may possibly change our mind.

Yet the discussion about these two views often disregards a bunch of psycholinguistic and cognitive studies that have shown that nonstrategic validation processes occur online, during text comprehension, leading for instance to slower lexical decisions on words presented in incongruent contexts (West and Stanovich 1982) and interference by implausible statements on positive responses in a epistemic "Stroop" task (e.g., Isberner and Richter 2013, 2014; Piest et al. 2018; Weil and Mudrik 2020). These results are consistent with the idea that comprehension of a statement cannot happen without verification of its overall meaning and of its correspondence with language, as constrained by world knowledge, namely reality as we believe it to be. Actually, our world knowledge, our beliefs, do not influence comprehension as output, because they do not operate after comprehension but during comprehension, as a process.

So, the alternative is: do we first comprehend something, and afterwards we believe it or not, i.e., accept it as true vs. reject it as false? Or are we verifying its truthiness when we are still inferring its meaning? The latter, single-stage, view rejoins Spinoza in one sense: we unconsciously use our beliefs when we are processing a message to comprehend it.

Let us now take a look at some of the experimental paradigms that specifically aimed at examining belief fixation. Gilbert et al. (1990) asked participants to learn words from the Hopi language by presenting them written sentences with the form "A (e.g., tarka) is a (e.g., wolf)". This learning task was followed, in an aleatory sequence, for one third of the trials by the information "true", another third the information "false", and the remaining third by a blank screen. After this, the sentences were presented again for a 
further task. On one third of the critical trials (true and false), an interfering tone was presented after the information "true" or "false", and the participants had to respond to it as fast as possibly by pushing a button. At the end of this task, the participants were again presented with all the sentences to indicate if they had been signaled as true or false. The tone did not affect accuracy in memory performance on true propositions recalled either as true or as false but had a clear effect on false propositions: while, without the tone interference, correct recall of false propositions as "false" was as good as correct recall of true propositions as "true", with the tone interference there was a $23 \%$ advantage in recalling true propositions as "true" compared to recalling the false propositions as "false". Conversely, whereas without the tone, incorrect responses were only around $20 \%$ in both directions ("false" for true and "true" for false), with the interfering tone, responding "true" for false propositions reached $33 \%$ whereas there were only $17 \%$ of "false" responses for true propositions.

The fact that interfering tones induced participants to mistake false claims as true, but not true claims as false, supports the Spinozan position. True or false, the information is (or tends to be) initially represented as true and maintained as true at least until the response. This inclination towards believing has been called the truth bias. Note that Gilbert et al. (1990) experiment was not a reaction time one: the participants had until nine seconds to respond after each presentation (including the tone task). What did the final task involve? It involved language comprehension, but the only difficulty was to remember the relation between a just-learned new word and a well-known word of the participant's lexicon. Sentence comprehension was not tested, only word learning.

Usually, language comprehension involves, at least, representing the meaning conveyed by a proposition or a sentence. In the situation used by Gilbert et al. (1990), there is no indication that world knowledge was activated. Each new word corresponded to a real known word, but the knowledge relative to the known word was not necessarily activated, probably just an image beyond its phonological and orthographic representations. What would Descartes and Spinoza call language comprehension? Most probably they were not concerned by word processing or the knowledge of the referent of a few learned words. If they could read Gilbert et al.'s paper, both would find strange to infer what happens in language comprehension by presenting unrelated written sentences (which happens in many psycholinguistic experiments) of which the only relevant information was whether a Hopi word corresponded to an English word. They would have probably expected an investigation on how ideas develop across related sentences, the truth or the falsity of a written or spoken reasoning. They would have felt themselves very uncomfortable and disappointed by the kind of questions that were raised almost four hundred years upon them, especially learning that such questions were inspired by their own work-how is it possible? Descartes, at least, would have reacted that way. Spinoza, yet, would probably have questioned what were the origins of the passion underlying the choice of such an experiment with the aim of testing his two hypotheses, namely unity (comprehension is acceptance) and temporal asymmetry (acceptance precedes rejection), without using comprehension (or even memory) of related meaningful sentences.

Who is "we" in "we believe"? Does literacy play any role?

Although the study described above is the one usually cited, Gilbert et al. (1990) presented two other studies that are more convincing as they require reference to world knowledge. We briefly refer study 3, "The Furry Glark Experiment", in which participants initially learned about the morphology and the habits of an animal called "glark". In the test phase, before the presentation of a (true or false) proposition about the glark, there was either an instruction to read it and press a key after reading, followed by an instruction to assess it as true or false (reading-then-assessment), or the question "is the following sentence true?" once or twice (assessment only or double assessment). For true propositions, all three types of trial elicited more than 90\% correct responses (initial reading and initial assessment eliciting about 96 and 92\%, respectively). For false propositions, whereas the trials involving double assessment elicited round $90 \%$ correct, a single assessment reduced the score to $83 \%$, and just reading before assessment reduced it even more, to $75 \%$.

The important information is that initial reading, compared to initial assessment, reduced significantly the probability of detecting falsity, which is consistent with the idea that reading allows comprehension but 
strongly reduces success in subsequent verification of possible falsity. This is in agreement with the Spinozan idea that comprehending is accepting and accepting is believing. In the initial comprehension stage, we believe what we are presented with, we do not operate any epistemic verification, or not much. Looking for falsity is a later process, distinct from comprehension and intentional. More recent studies provided even stronger evidence for the idea that people are truth biased toward incoming information. They suggested that the truth bias is much more general that argued by Gilbert et al. (1990), being independent from distraction and cognitive load (e.g., Pantazi et al. 2018; but see Nadarevic and Erdfelder 2019). No wonder that credulity, the great enemy of wisdom, "poisons and polarizes today's public life", making us live in a "gullible post-truth world" (Myers 2019). In fact, it seems that falsehoods are not corrected unless they are explicitly negated (Weil et al. 2020).

As we already noted, it is quite strange that roughly all the literature on rationality, including the experimental work we referred to, which almost always confronts the participants with written material, completely neglects one main characteristic of such participants: they are literate. And these studies also neglect the fact that to be literate is not a characteristic of the whole human species. As we already said, it actually is a characteristic of only a minority. Discussing about human rationality by examining only literates is as talking about the world without ever leaving our native village. Scientists do make universal claims about us, humans, without leaving their literate village. It is even more paradoxical when we think that scientists are themselves people whose work is entirely grounded on critical literacy and expressed via critical literacy.

Until the invention of writing and the spread of literacy, the human beings created and entertained myths that were guiding them, with no essential difference between humans and non-humans, and even the forest had an Anima (Descola 2005, pp. 37-39). Beliefs change. Most of us do not believe anymore (except in some pathologies), as the old Greeks believed short before the emergence of the alphabet, that we hear the gods' voices (although some want to make others believe it). Myths were useful in foragers societies: oral and visual information was couched in myths, providing a useful context (e.g.,
Sugiyama 2017), and listening to storytelling was particularly useful to exercise episodic memory in order to construct scenarios for future events (e.g., Sugiyama 2011).

Literacy promoted analysis: of speech, of language, of matter, of the dimensions of objects and beings, of thought, of emotions and feelings, of everything. Yet, from our experience with illiterates, both in conversations before and after testing sessions and in political encounters, we found that they can evaluate arguments, reveal disagreement, and counter-argue. Obviously, provided the vocabulary and the structure of the discourse are accessible, and if they surmount the feeling of being poorly educated compared to the literates they are discussing with. If they had learned English, they would understand Trump in a meeting, because Trump's language is close to the illiterates' language.

Who is dumb?

... But what do actually illiterate people understand? According to some researchers, their poor performance in, for instance, awareness tasks, reflects the fact that they do not understand these tasks, due to their poor schooling and unfamiliarity with settings and materials (Koopmans 1987). This idea is contradicted by the fact that their performance depends mainly on the level of the units to be manipulated and little on the task form. For instance, illiterates perform very poorly on deletion task when the target segment is a consonant, but much better with vowels or syllables (Morais et al. 1986). Koopmans (1987) argument is just but one illustration of the frequent confusion between lack of schooling or illiteracy and stupidity, which sometimes has been cynically used for political aims.

At the time of the First World War and just after it, there has been in the US a hot discussion about immigration, which involved two main concepts: intelligence and literacy. The sources of immigration changed radically between the last two decades of the nineteenth century and the beginning of the War in 1914, with the British and German entering with percentages above 20 and even 30\% until 1892 but then decreasing to much less than $10 \%$. At the same time, the Italians and people from Eastern Europe increased from less than 5\% to more than $20 \%$ (Young 1922). Not accidentally, it was at that time that the first 
tests of skills were used in the US. The test created by Binet in 1905 was imported in US by Terman in 1916; it was the origin of the intelligence scales and of the IQ, and the first version of the Wechsler battery was released in 1939. More important for our present purpose, during the First World War, the US Army developed two tests with the support of Robert Yerkes, at that time president of the American Psychological Association. Using a new method, multiple-choice, the Army Alpha and Army Beta group-administered tests aimed at determining the recruits' capability of serving, job classification, and potential for a leadership position. The first was applied to people who could read, the Army Beta to illiterates or those who did not speak English. It consisted of supplying the missing parts of pictures, trace one's way through mazes, count cubes variously arranged, etc. The two tests were assumed to be equal in evaluating intelligence (Sweeney 1922), which implies that literacy was considered as not influencing intelligence. In the US army, 360,000 men of foreign birth were tested: almost $46 \%$ were found to perform at D level or below, ${ }^{3}$ which represents "inferior" or "very inferior" intelligence (mental age $<11$ years). While people from countries such as Russia and Poland counted from 60 to $70 \%$ in the mental age ranging from 7 to 11 years, and less than $3 \%$ above 16 years, those from Holland and England together were around 9\% in the low range and $15 \%$ in the high range. ${ }^{4}$ The puzzling

\footnotetext{
3 The numerical scores were translated into letter grades for practical military purposes.

${ }^{4}$ Here are some of Sweeney's (1922, pp. 605-611) comments: "It is not wholly because conditions in Europe are so unfavorable that the lower groups cannot make a living, but rather because their mental unfitness prevents them from prospering in the old country as it does in the United States. (...) The groups at the lower end of the psychological scale are the undesirable. They are distinctly sub normal, and as such cannot react favorably in their new environment. They are wholly inadaptable. It is impossible without a psychological test to determine who belong to these groups (...) This group is wholly illiterate. (...) They can't form a judgment, for them to act or to refrain from action is largely a reflex. (...) They think with the spinal cord rather than with the brain (...) Their minds do not rise to the level of the abstract, and all their problems are referred back to past experiences, upon which alone they form their judgments. In this class belongs the moron, whose intellectual level seldom exceeds that of eleven years. The moron is marked by a low intellectual level combined with an emotional instability and lack of inhibition that leads to infraction of social customs and laws. He is a reflex arc, rather than a reasoning being. (...) Unable to read books or papers, they
}

finding was that the Army tests classified the Jews as quite low in intelligence. This was accounted for by the idea that a low mean does not prevent the occurrence of some geniuses. There is, however a more credible explanation: The Jews, like the Latin and the Slavic, were recent immigration, whereas the great wave of English, Teutonic and Scandinavian was more ancient. Yerkes himself observed that scores increased consistently with time spent in US. But Yerkes and the apologists of hereditarianism persisted: The correlation with length of residence resulted from the fact that those with better genes came first.

Concerning children, more precisely first-graders, Young (1922) reported on their scores in the BinetSimon test: a median IQ of 78 for the Spanish, 84 for the Portuguese and the Italian (Southern Italy), but of 105 and 106, respectively, for the North-European and American of North-European ancestry (all mentioned as "Racial stocks"). A retest 5 years later still showed a large difference, thus consistent with the idea that IQ is innate. Young concluded that "The evidence at hand seems sufficiently valid to establish that general as well as specific abilities are transmitted by heredity." (p. 419).

The biologist Stephen Jay Gould (1981, 1982) argued against the hereditarian school of psychology. To him, the testing approach conducted by Yerkes in the Army was flawed. The Alpha tests reflect "education more than inherited intelligence". Consider the Alpha analogy: "Washington is to Adams as first is to second...", or the multiple-choice item "Christy Mathewson is famous as: writer, artist, baseball player, comedian". Moreover, "many should have

Footnote 4 continued

cannot get in proper touch with their surroundings. Being constitutionally inferior, they are necessarily socially inadequate. They cannot conform to the normal customs of society. They are incapable of becoming good citizens by reason of intellectual deficiency, and they should be allowed no place in this country and no voice in its affairs. (...) It is very evident that these groups could not be otherwise than illiterate. Education can be received only by those who have the intelligence to receive it. It does not create intelligence. That is what one is born with. (...) It is useless to clamor for education of the lower groups. They cannot receive it. What is of more urgent necessity is education of the higher groups to fuller comprehension of their environment, to greater realization of the duties and obligations of citizenship (...). It is time to awaken to the necessity of protecting this country from the influx of the worthless. Unless we do so we shall degenerate to the level of the Slav and Latin races, with their illiteracy, ignorance and consequent degradation". 
taken Beta but received only Alpha and scored abysmally_primarily poorly educated Blacks and immigrants with a poor command of English". The Beta itself required pencil work, and an examiner commented: "It was touching to see the intense effort of men who never before had held a pencil in their hands".

Yet those tests led to the Immigration Restriction Act of $1924^{5}$ affecting the life of millions of people. According to Gould, the eugenicists "won one of the greatest victories of scientific racism in America history". "AAmerica must be kept American', proclaimed (the president) Calvin Coolidge as he signed the bill". What prevailed was the idea that immigration into the US should be selective: only the intelligent ones should be admitted. Hoyt (1916, p. 463) argued that "The literacy test will bring about a substantial reduction in the number of immigrants admitted to this country", justifying it with the supposition that "if applied during the ten years from 1899 to 1909 it would have excluded at least $26.6 \%$ of our total immigration". But the eugenicists were opposed to a literacy test in place of the discriminative quotas based on assumed intelligence, arguing that, "due to inequality of educational opportunities in Europe, it is likely that persons of good intelligence will be barred because they cannot read or write while persons really subnormal (...) are able to pass the meager demands on their reading and writing abilities at the gates of the country" (Murdoch 1920). Quite clearly, education and literacy were presumed to have strictly no effect on "intelligence", which was fixed forever by the genes.

Sometimes, the "if" questions are worth. If there had been no such classification according to a presupposed innate intelligence, perhaps the subsequent events would have been less tragic for millions of people: "Throughout the 1930s, Jewish refugees, anticipating the holocaust, sought to emigrate, but were not admitted. The legal quotas, and continuing propaganda, barred them (...). Estimates suggest that the quotas barred up to six million southern, central, and eastern Europeans between 1924 and the outbreak of the Second World War (...). We know what

\footnotetext{
5 This was a US federal law that prevented immigration from Asia, set quotas on the number of immigrants from the Eastern Hemisphere, and provided funding and an enforcement mechanism to implement a ban on other immigrants.
}

happened to many who wished to leave but had nowhere to go. The paths to destruction are often indirect, but ideas can be agents as sure as guns and bombs" (Gould 1982, p. 352).

That was one century ago. Presently, the grades of Army tests are no more necessary. There is the Wechsler's IQ, there is the non-verbal Raven test, all anterior to the post-behaviorism progresses of cognitive psychology, and the faith persists on the existence of a "general intelligence" transmitted through the genes. The project of enrichment of the US dominating the rest of the world also persisted. And today, in US but also in Europe, we are seeing and hearing similar ideas as the one we reported above. History tends to repeat because the same interests activate the same means.

These ideas were manifest in a Ph.D. dissertation in Public Policy titled IQ and Immigration Policy, presented in 2009 at Harvard University by J. Richwine. The author thanks the American Enterprise Institute for its support and Ch. Murray for his advising. Ch. Murray was the co-author, with R. Herrnstein, of The Bell Curve (1994). Intelligence, genetically inherited and unchangeable by home or school education, is the variable distinguishing an intellectual elite and an intellectual under-class and consequently the rich and the poor, and, by linking intelligence genes and race, the White and the Black.

In 1965 the US had abolished the national origin quotas and changed the highly restrictive policy of visas for immigrants, thus allowing a less educated and wealthy immigration. According to Richwine (2009, p. 3), IQ is "a reliable and valid operational measure of general intelligence". Given that "the average IQ of (the new) immigrants is substantially lower than that of the native population" (in the low $90 \mathrm{~s}$, with the Mexican in the mid-80 s), and that "the difference does not disappear by the second or the third generation", "the result is a lack of socioeconomic assimilation (...), underclass behavior and loss of social trust." Richwine (pp. 3-5) found the solution to this problem: attracting a different kind of immigrant, namely the poor "with great potential." He did not rule out the role of material environment and education, and was aware that "inadequate nutrition, healthcare and early schooling could depress immigrant IQ scores". The project was therefore to give "high IQ citizens of poor countries the chance to get an education that matches their cognitive skill". This 
"would be a win-win situation": the use of IQ tests would be egalitarian because it gives an opportunity even to those without access to good education. Talking about skill and skill tests rather than IQ, because of the negative reactions to this term, he mentioned the highly g-loaded Ravens' matrices, which "require no literacy whatsoever" (ibid., p. 130), "no knowledge of words or numbers" and "ensures cultural fairness" (ibid., p. 133). These notions of egalitarianism and cultural fairness are indeed very peculiar, and it is clear that literacy has no place in this ideology.

Nowadays, many research papers continue to support the idea that intelligence is genetic, but in a more sophisticated way. For example, Lynn (2006) developed the cold winter theory according to which cold environments exerted a selective pressure on cognitive capacities, favoring the Sapiens who migrated into the north of Europe and then into Asia. In a paper $^{6}$ synthesizing the book he wrote with Vanhanen (Lynn and Vanhanen 2002), IQ and the wealth of nations, Lynn took on his side Adam Smith as the latter wrote that the skills of the population are the principal factor responsible for national differences in incomes and wealth. Besides, arguing against Kofi Annan (at that time Secretary-General of the $\mathrm{UN}$ ), to whom intelligence is equally distributed among the world's people, Lynn added that this is incorrect as "it is known in psychology" (...) "that there are large differences in average levels of intelligence between different nations". He concluded that "the major reason for this association is that people with IQs can acquire complex skills that command high earnings and that cannot be acquired by those with low IQs". This causal sequence (high IQs $\rightarrow$ higher skills $\rightarrow$ higher earnings) could not look more rational. The problem, however, is twofold: first, intelligence is itself defined by its measure, IQ; second, it may well be that the arrow's direction is inversed, namely that it is higher skills that raise IQ performance. And what is mainly responsible for higher skills? We bet literacy and critical literacy.

Before putting Lynn aside, let us remind with G. Berhanu (2007) that such ideas led to Nazis' racist ideology of inferior races and their justification of the murder of Jews, Gypsies and homosexuals, plus all the

\footnotetext{
${ }^{6}$ https://www.rlynn.co.uk/index.php?page=intelligence-andthe-wealth.
}

others, most of them communists, who were murdered in the camps. Regarding Africa's position in terms of IQ, Berhanu recalls the centuries of Africans' oppression, colonization and exploitation, making the superiority of whites a "dying mirage" (Diamond 2005). After elaborating more the Africa's situation, Berhanu adds that "for people like Kanazawa (2006) and Lynn and Vanhanen (2002) this disturbing image of poverty, inequality, and violence does not cause high infant mortality rate, low life expectancy, or low per capita income. They claim it is the average intelligence of the nations that causes all this misery." (p. 4). He adds, proving that irony is in some cases a necessary part of critical literacy: "One would expect that in Roman times the Britons and Germans would have been put to shame on most "intelligence tests" devised by the Greeks and the Romans and that in the eighth or ninth centuries most western Europeans would have lagged badly behind citizens of the Islamic world where literature, science, and arts then flourished." (p. 4). "Is learning a reflection of intellectual capacity (intelligence)? Or is intelligence in some measure the product of learning?" (p. 5). "The different forms, figures and diagram that are easy to grasp by people who come from a "carpentered" society", rather than from the villages of Gondor where people's physical surroundings and implements, including play materials, are less geometrically formed. How could one dare to say these tests are culture-free? (in Gondor lived the Ethiopian Jews, whom Berhanu had well known). And he recalls Franz Boas: "Mind, independent of experience, is inconceivable?" (pp. 6-7); "The countries of Africa with IQs 50-69 (seven in number) are referred to as "feeble minded" and others with IQs of 70-79 as "border line deficient". (...) Can the authors claim that they are doing just pure science with no implications or consequences for over one billion dark skinned people and a billion more colored people?" (p. 16).

Science? "In the words of Gould (1981/1996), Sir Cyril Burt juggled, finagled, and fabricated data to support his own research in an attempt to confirm the superiority of the Caucasian race and place North Europeans at the apex of civilization and the rest of the human race lagging far behind." (Berhanu 2007, p. 17). As Berhanu (2007, p. 16) notes, "one major fallacy in their argument is that they present no evidence that intelligence is substantially heritable and that intelligence is differentially distributed among the 
world's people (...) the principal evidence that they refer to again and again is that identical twins reared apart in differing life circumstances are much more similar intellectually than fraternal twins reared under the same roof. This statement was originally made by Burt who has been accused of distorting the data". Based on Crane (1994), Berhanu recalls that "Those data are virtually worthless because so many of the twins were adopted into extremely similar, or even related, families. Moreover, there are reasons to believe that some of the twins in these studies may not really have been separated" (p. 17).

To complete the scenario, it is worth mentioning that Lynn and Vanhanen (2002) study was supported by the Pioneer Fund, which also publishes a journal, Mankind Quarterly, "aptly described as a fascist journal, closely linked with the eugenics movement.". The fund "has specialized in supporting research that seeks to prove the genetic and intellectual inferiority of blacks (...)" (Tucker, 2002). As Gresson et al. (1997) pointed out, these are measured lies, or, according to Tucker (1994, p. 4), the product of an "obsession with proving that minorities, poor people, foreigners, and women are innately inferior to upperclass white males of northern European extraction". According to Tucker, who provides an overview of racial research from Condorcet $(1795)^{7}$ to the present, the claim that one group is genetically less desirable or capable than another has invariably been part of what Condorcet called an attempt "to make nature herself an accomplice to political inequality" (p. 5).

Science is conducted and written by literate people who do not live above the social and political antagonisms. Even if it may be considered as a form of critical literacy, it is obvious that science itself deserves to be critically examined. The role of science in the human literate culture and in the future of our species is, undoubtedly, of a great responsibility.

Yet we cannot leave this issue without adding some words about more recent work. Rindermann et al. (2012a) argued in the same sense as Lynn; and Rindermann (2012b) defended that "not only wealth, but even capitalism, depends on the size and cognitive level of a high ability groups within Society. Capitalism in modernity is a cognitive one!” (p. 112).

\footnotetext{
7 The Condorcet text can be consulted at https://oll.libertyfund. org/titles/condorcet-outlines-of-an-historical-view-of-theprogress-of-the-human-mind.
}

According to him, innate intelligence interacts with education and "furthers rational and autonomous thinking" (p. 110), but the proxy for education is years of schooling, and the word "literacy" is completely absent.

We must take into account that genetic heritability is calculated by comparing monozygotic to dizygotic twins (the dizygotic having less genes in common), but this heritability may manifest itself differently for different abilities, including cultural or learned abilities. This was clearly shown by Kovas et al. (2013). Our "natural" dispositions to learn depend on what we learn. In the first grades (from Grades 2 to 4), our heritability seems to play a much greater role for literacy and numeracy than for the presumed $g$ factor (general intelligence). The genes do not learn to read, but without genes we would not learn, so heritability only describes how our genes contribute to the similitude between us when we learn. Literacy and numeracy learning are highly constrained acquisitions, and therefore common genes explain more of the variability. But, once the basic literacy and numeracy abilities are acquired, the contribution of individual experiences with these abilities increases even when two individuals are monozygotic twins.

Explaining cognitive development by a juggling consisting of a double reduction, the inheritance, exactly like a patrimony, of a single general capacity-intelligence or $\mathrm{g}$ factor-, and its regulation by rich or poor genes, seems to be either a fairy tale or a witching nightmare. This story evokes others, it reflects and at the same time justifies another kind of inequalities, and both do correlate quite high. In any case, it is desperately too simple to assume that there is a single, dominant underlying ability such as the $\mathrm{g}$ factor that would affect task performance across domains. Recent studies tell a more reasonable story, the story of a rather complex and interactive developmental process that explain why there are often pervasive positive correlations between distinct cognitive abilities. As a matter of fact, in large longitudinal cohorts of adolescents, young adults, and 6-8 years old children, Kievit et al. (2017, 2019) observed that developmental changes in two core cognitive domains, vocabulary and reasoning (as measured by the matrix test), were better explained by a mutualism model, which proposes reciprocal 
developmental interactions between cognitive abilities during development.

How our Panglossian rational literate world can be made of so few critical literates

As we already commented on, nobody knows how many literates and critical literates there are in the world. Wealth and even health are quantified, not literacy. The only relevant databases are the PISA and Skills Matter, published every 3 years. In both cases only reading comprehension is examined. One knows that writing is more demanding than reading and, indeed, quite frequently writing skills are lower than reading skills. Unfortunately, without tests on written word recognition it is impossible to have precise information on the reading skills, namely whether the reader is what in cognitive psycholinguistics one calls a skilled reader.

PISA considers eight levels in reading comprehension. With a very low level of exigence, Level 3 could correspond to skilled reader, but it is improbable, as what is required is just capacity to locate, recognize and integrate pieces of information. It is not sure that at Level 3 most of the adolescents already access automatically the orthographic lexicon in the course of reading. Level 4 most probably allows the automatic lexical access as well as making inferences and hypotheses about a text, but not yet evaluate it critically. One of the tests for this level required to compare two letters posted on the Internet containing a proposal and argumentation for it; the students were asked to indicate the best one and why. If the students justified the choice of one because it directly addressed the readers, or of the other because it evoked a discussion more than a presentation of ideas, they received the maximum score, and if they simply said one was more persuasive or better written, they received 0 . This is not yet an indication of critical reading, which seems to be attained only at Level 5. In the last published 2019 results (relative to the 2018 testing, OECD 2019), across OECD countries (the most developed), about $53 \%$ of students were proficient at Level 3 or higher, about 27\% at Level 4 or higher, and about $10 \%$ at Level 5 or higher. Other, non-OECD, countries, included in the study, presented much worse scores. For example, in Brazil, only about $26 \%$ were proficient at Level 3 or higher, about $9 \%$ at Level 4 or higher, and about $2 \%$ at Level 5 or higher.
Compared to the OECD countries, the proportion of readers, from a modest to a high level, in a country, like Brazil, which is said to be emerging, thus decreases from half (Level 3) to a fifth (Level 5).

For the adults, the corresponding percentages were even lower, and it is worth noting that in Skills Matter (OECD 2016) there was no indication of an interest concerning critical literacy. We broadly summarize the enormous disparities in educational level through an increasing percentage stair from the educationally rich to the poorest: about $10 \%$ of elite and experts whatever the domain of specialization, $20 \%$ of competent professionals, $30 \%$ of specialized employees and workers, and $40 \%$ of unskilled workers, precarious, unemployed, indigents, homeless, beggars, prisoners. This "(il)literate tour" will be consolidated given that there are no plans to mass education, to offer poor literates efficient programs including, beyond literacy, stimulation to reason and debate collectively about their present situation, their future and the future of the human species. The political elites, acting for the benefit of the capitalists, on which their positions depend, have padlocked all means of overcoming this situation. It is not from the political elites that one can expect a serious improvement in education, which should consist, at least, in ensuring for all children and adolescents literacy abilities, a program of activities for the development of critical literacy, and courses on humanities (philosophy, anthropology and ethnology, history, sociology).

Much on the contrary, these topics are, for obvious reasons, disappearing from the general curricula. Young women and men must be amputated from our (their) origins and cultural process, to allow them to assimilate exclusively the values and aims of the global capitalist project, regardless of whether they will form the elites or an easily malleable multitude. Critical literacy, if it generalizes, will become a challenge and a threat to the power of the dominant classes. These and the high middle class, which aspires to join them, and the median and part of the low middle classes, which rely on superior education to get into the elites, but, above all, fear to fall into poverty, do not have the slightest interest in the generalization of literacy and critical literacy. Social competition is not consistent with high literacy for everybody. Whatever their degree of overlap, the wealthy classes and the political elites, which decide on educational policies, have all interest in maintaining a very high level of 
education, especially in innovative technology and high administration and management (political, economic and financial), for a minority, and low and very low (the so-called professional and technique) levels for the large majority of the children and young people.

Who governs us? What kind of people form the parliaments and are responsible for making laws and take the most important resolutions? Bovens and Wille (2017) showed quite clearly that the so-called West Europe democracies are actually diploma democracies, "governed by a select group of well-educated citizens" (and, according to us, a selected group). To give a few examples: "In the British House of Commons, after the 2015 elections, nine out of ten MPs were university graduates"; "after the 2012 elections, almost $97 \%$ of the members of the Dutch Tweede Kamer had attended college or graduate school and more than $90 \%$ had formally acquired at least a college degree-the highest percentage since the introduction of universal suffrage in 1918". The authors comment (p. 2) "This is not because everybody goes to college nowadays-over $70 \%$ of the electorate in Western Europe is still only educated up to secondary level, at the highest." Bovens and Wille mentions M. Young's satirical essay The rise of the meritocracy, published in 1958 after the manuscript has been turned down by 11 publishers. It was a fictional report situated in 2034 and showing the transformation of the British class system from an aristocracy into a meritocracy. It became normal to be ruled by the "meritorious". This is an issue for critical literacy, to be discussed by all the people, in particular the new generations, including the enormous contingent of children and adolescents who receive poor instruction in poor conditions and by poorly formed teachers, at least infinitely poorer than the future meritorious among which are recruited the meritocrats.

Can we teach critical literacy and argumentation to all?

Our aim is not to present here a review of the literature on the effective strategies for teaching critical literacy and argumentation but rather to illustrate the fact that they can be taught at all educational levels, and even on severely disadvantaged population. This is shown for instance by an almost unnoticed US educational research on residents of a juvenile detention facility, where, once incarcerated, these young people "lose all control of their lives" (De Fuccio et al. 2009).

The participants, aged from 12 to 18 years, largely African Americans or Hispanic, had committed status offenses among the younger and drug sales, aggravated assault, rape and murder among the older. Their average reading and mathematics skills corresponded to the fourth grade, whereas they should be approaching the end of secondary school. They had a four-hour school day five days per week. The intervention designed by the second author, the famous educational psychologist D. Kuhn, intended to develop argument skills through dialogic argumentation with a peer in the context of small groups. The activities and goals included: (1) generating reasons; (2) elaborating them; (3) evaluating them; (4) supporting them with evidence; (5) developing them into an argument (6) examining and evaluating opposing-side ones; (7) generating counterarguments to others' ones; (8) generating rebuttals to others' counterarguments; (9) contemplating mixed evidence; (10) conducting and evaluating two-side arguments. All were centered around a theme, capital punishment, which significance was discussed. The coach began by talking about the power of competing and asserting oneself through ideas rather than physical power.

Compared to control participants, those who received this intervention had almost twice as long dialogs among them, expressed twice as many unique reasons, required much less clarifications, made many more counterarguments to the opponent (86 vs. 17\%), made more rebuttals $(3.7$ vs. 1 , with 93 vs. $21 \%$ making at least one successful rebuttal) and produced more distinct reasons per dialog (about 9 vs. 4). Beyond these large differences, the authors stressed the contribution, to the capacity of self-control, of the cognitive demands for perspective-taking-representing the thoughts of the others-and for articulating own thoughts and reasons. Argumentation and counter-argumentation practice also helped to understand the difference between criticizing an idea and criticizing the person that emits it.

This suggests an immediate reaction: "Yes, we can!", followed by a more realistic "Yes, we could if..." If we had, not a meritocracy, a diploma pseudodemocracy, coupling politicians and capitalists, but a real democracy, offering education for the poor people with the same quality as the one reserved to the high 
class families, and an open debate in school and in society about human values.

We do not think that science and scientists, including cognitive and neurocognitive ones, can perseverate in their blindsight vision responding to, surely, very important scientific questions, but letting most of the humans they cross miss the same critical literacy capacities they developed because-it was not just that, of course, but it was a necessary conditionthey had the opportunity to.

You do not care? Perhaps you should. Indeed, poor education level is negatively associated to analytic thinking and open-mindedness, leading to greater intuitive thinking and hence credulity (e.g., Van Prooijen 2017). Consistently, education level is negatively associated with people's superstitious beliefs (e.g., in the power of lucky charms such as a mascot or a talisman, Mocan and Pogorelova 2017), beliefs in paranormal phenomena (e.g., Aarnio and Lindeman 2005) and conspiracy theories (e.g., Douglas et al. 2016; Freeman and Bentall 2017; Mancosu et al.; Van Prooijen 2017; Uscinski and Parent 2014), and, together with total media consumption, beliefs in fake news (e.g., Allcott and Gentzkow 2017). This is tremendously important for all of us, given the many detrimental implications of these irrational beliefs for public health (cf. e. g., medical conspiracy theories: Oliver and Wood 2014), political participation and climate change (e.g., Jolley and Douglas 2014), and radicalization (Van Prooijen et al. 2015).

Education may provide people with a set of cognitive and emotional attributes that enable them to resist these various forms of information disorder (Wardle and Derakhshan 2017). Literacy, at least high-level literacy, is one of these tools, as illustrated by the fact that greater knowledge about the news (or news media literacy) decreases conspiracy theory endorsement (Craft et al. 2017).

Acknowledgements J. Morais is Emeritus Professor at Université Libre de Bruxelles (ULB) and Invited Professor at Unescog (CRCN, ULB). R. Kolinsky is Research Director of the Fonds de la Recherche Scientifique-FNRS (FRS-FNRS), Belgium. Preparation of this paper was supported by a Concerted Research Action grant of the Belgian French community attributed to R. Kolinsky and O. Klein (The Socio-Cognitive Impact of Literacy).

\section{Compliance with ethical standards}

Conflict of interest On behalf of both authors, the corresponding author states that there is no conflict of interest.

Open Access This article is licensed under a Creative Commons Attribution 4.0 International License, which permits use, sharing, adaptation, distribution and reproduction in any medium or format, as long as you give appropriate credit to the original author(s) and the source, provide a link to the Creative Commons licence, and indicate if changes were made. The images or other third party material in this article are included in the article's Creative Commons licence, unless indicated otherwise in a credit line to the material. If material is not included in the article's Creative Commons licence and your intended use is not permitted by statutory regulation or exceeds the permitted use, you will need to obtain permission directly from the copyright holder. To view a copy of this licence, visit http://creativecommons.org/licenses/by/4.0/.

\section{References}

Aarnio, K., \& Lindeman, M. (2005). Paranormal beliefs, education, and thinking styles. Personality and Individual Differences, 39, 1227-1236.

Adams, M. J. (1990). Beginning to read: thinking and learning about print. Cambridge, MA: MIT Press.

Allcott, H., \& Gentzkow, M. (2017). Social media and fake news in the 2016 election. Journal of Economic Perspectives, 31, 211-236.

Anderson, G. L., \& Irvine, P. (1993). Informing critical literacy with ethnography. In C. Lankshear \& P. L. McLaren (Eds.), Critical literacy: Politics, praxis, and the postmodern (pp. 81-104). Albany: SUNY Press.

Beck, J. (2013). Why we can't say what animals think. Philosophical Psychology, 26, 520-546. https://doi.org/10. 1080/09515089.2012.670922.

Bereiter, C., \& Scardamalia, M. (1987). The psychology of written composition. Hillsdale, NJ: Lawrence Erlbaum.

Berhanu, G. (2007). Black intellectual genocide: An essay review of IQ and the wealth of nations. Education Review, 10, 1-28.

Bergen, B. K., Lau, C., \& Ting, T. (2012). Writing direction affects how people map space onto time. Frontiers in Psychology, 3, 109. https://doi.org/10.3389/fpsyg.2012. 00109.

Bertelson, P. (1972). Listening from left to right versus right to left. Perception, 1, 161-165.

Biemiller, A. (1977-1978). Relationships between oral reading rates for letters, words and simple text in the development of reading achievement. Reading Research Quarterly, 13, 223-253.

Bishop, E. (2014). Critical literacy: Bringing theory to praxis. Journal of Curriculum Theorizing, 30, 51-63.

Blakeney, E. H. (Ed.). (1928). Horace on the Art of Poetry. London: Scholartis Press.

Baker, T. E. (1993). A review of Corpus Juris Humorous. Texas Tech Law Review, 24, 869-873. 
Boileau. (1674). Art Poétique, in Boileau, Oeuvres Complètes, Paris: Bibliothèque de la Pléiade (no 188, published in 1966. For the English translation, see https://izquotes. com/quote/20221).

Bovens, M., \& Wille, A. (2017). Diploma democracy. The rise of political meritocracy. Oxford: Oxford University Press.

Buyse, F. (2017). A new reading of Spinoza's Letter 32 to Oldenburg: Spinoza and the agreement between bodies in the Universe. In G. Boros, J. Szalai, \& O. Toth (Eds.), The concept of affectivity in modern philosophy. Budapest: Eötvös Lorand University.

Cary, L. (1988). A análise explicita das unidades da fala nos adultos não-alfabetizados. (The explicit analysis of the speech units in the unalphabetized adults). Ph.D. Thesis, Lisbon: Universidade de Lisboa.

Cassata-Widera, A. (2008). Concept mapping with young children: From representation to metacognition. WarnerSchool Ph.D. Dissertation thesis. https://hdl.handle.net/ $1802 / 6700$.

Castelain, T. (2014). Raisonnement et argumentation : Une approche interculturelle et développementale. Ph.D. Thesis. ISC, Université de Lyon.

Castelain, T., Bernard, S., \& Mercier, H. (2018). Evidence that two-year-old children are sensitive to information presented in arguments. Infancy, 23, 124-135. https://doi.org/ 10.1111/infa.12202.

Castro-Caldas, A., Petersson, K. M., Reis, A., Stone-Elander, S., \& Ingvar, M. (1998). The illiterate brain. Learning to read and write during childhood influences the functional organization of the adult brain. Brain, 121, 1053-1063. https://doi.org/10.1093/brain/121.6.1053.

Chafe, W. L. (1982). Integration and involvement in speaking, writing, and oral literature. In D. Tannen (Ed.), Spoken and written language. Norwood: Ablex.

Chaffee, D., \& Lemert, Ch. (2016). Structuralism and poststructuralism. In B. S. Turner (Ed.), The New Blackwell Companion to Social Theory (pp. 124-140). Hoboken: Blackwell.

Chokron, S., \& Imbert, M. (1993). Influence of reading habits online bisection. Cognitive Brain Research, 1, 219-222.

Counihan, M. E. (2008). Counihan, M. E. (2008). Looking for logic in all the wrong places: an investigation of language, literacy and logic in reasoning. Ph.D. Dissertation. Institute for Logic, Language and Computation.

Craft, S., Ashley, S., \& Maksl, A. (2017). News media literacy and conspiracy theory endorsement. Communication and the Public, 2, 388-401. https://doi.org/10.1177/ 2057047317725539.

Crane, J. (1994). Exploding the myth of scientific support for the theory of black intellectual inferiority. Journal of Black Psychology, 20, 189-209. https://doi.org/10.1177/ 00957984940202007.

Dabrowska, E. (1997). The LAD goes to school. A cautionary tale for linguists. Linguistics, 35, 735-766.

Dabrowska, E., \& Street, J. (2006). Individual differences in language attainment: Comprehension of passive sentences by native and non-native English speakers. Language Sciences, 28, 604-615.

Davidson, D. (1982). Rational animals. Dialectica, 36, 317-327.
Davis, H. (1997). Ordinary people's philosophy: comparing lay and professional metalinguistic knowledge. Language Sciences, 19, 33-46.

de Bie, H., Wilhelm, P., \& van der Meij, H. (2015). The Halpern critical assessment: Toward a Dutch appraisal of critical thinking. Thinking Skills \& Creativity, 17, 33-44. https:// doi.org/10.1016/j.tsc.2015.04.001.

Despret, V. (2008). The becomings of subjectivity in animal worlds. Subjectivity, 23, 123-139. https://doi.org/10.1057/ sub.2008.15.

Diamond, J. (2005). Collapse: how societies choose to fail or succeed. New York, NY: Viking.

De Fuccio, M. A., Kuhn, D., Udell, W., \& Callender, K. (2009). Developing argument skills in severely disadvantaged adolescent males in a residential correctional setting. Applied Developmental Science, 13, 30-41. https://doi.org/ 10.1080/10888690802606750.

Dehaene, S., Cohen, L., Morais, J., \& Kolinsky, R. (2015). Illiterate to literate: Behavioural and cerebral changes induced by reading acquisition. Nature Reviews Neuroscience, 16, 234-244. https://doi.org/10.1038/nrn3924.

Dehaene, S., Pegado, F., Braga, L. W., Ventura, P., Nunes, G., Jobert, A., et al. (2010). How learning to read changes the cortical networks for vision and language. Science, 330, 1359-1364. https://doi.org/10.1126/science.1194140.

Demoulin, C., \& Kolinsky, R. (2016). Does learning to read shape verbal working memory? Psychonomic Bulletin \& Review, 23, 703-722. https://doi.org/10.3758/s13423-0150956-7.

Descartes, R. (1934). Reply to Objections. In The Philosophical Works of Descartes, Vol. II, Haldane \& Ross (trans.) (pp. 210-211), Cambridge: Cambridge University Press.

Descartes, R. (1970). Letter to the Marquess of Newcastle. In Philosophical Letters. Oxford: Oxford University Press.

Descola, P. (2005). Par-delà nature et culture. Paris: Gallimard. [English translation: Beyond nature and culture. University of Chicago Press, 2013].

Destutt de Tracy. (1796). Mémoire sur la faculté de penser [Dissertation on the faculty of thinking]. Mémoires de l'Institut National, I, pp 283-450.

Dias, M., Roazzi, A., \& Harris, P. L. (2005). Reasoning from unfamiliar premises: a study with unschooled adults. Psychological Science, 16, 550-554. https://doi.org/10.1111/j. 0956-7976.2005.01573.x.

Dijksterhuis, A., \& Nordgren, L. F. (2006). A theory of unconscious thought. Perspectives on Psychological Sciences, 1, 95-109. https://doi.org/10.1111/j.1745-6916. 2006.00007.x.

Dobel, C., Enriquez-Geppert, S., Zwitserlood, P., \& Bölte, J. (2014). Literacy shapes thought: The case of event representation in different cultures. Frontiers in Psychology, 5, 290. https://doi.org/10.3389/fpsyg.2014.00290.

Douglas, K. M., Sutton, R. M., Callan, M. J., Dawtry, R. J., \& Harvey, A. J. (2016). Someone is pulling the strings: Hypersensitive agency detection and belief in conspiracy theories. Thinking and Reasoning, 22, 57-77. https://doi. org/10.1080/13546783.2015.1051586.

Drucker, H. M. (1972). Marx's concept of ideology. Philosophy, 47(180), 152-161.

Ehri, L. C., \& Rosenthal, J. (2007). Spellings of words: A neglected facilitator of vocabulary learning. Journal of 
Literacy Research, 39, 389-409. https://doi.org/10.1080/ 10862960701675341.

Evans, J., St, B. T., Barston, J. L., \& Pollard, P. (1983). On the conflict between logic and belief in syllogistic reasoning. Memory \& Cognition, 11, 295-306. https://doi.org/10. 3758/bf03196976.

Evans, J., St, B. T., \& Over, D. E. (1996). Rationality and reasoning. Hove: Psychology Press.

Fodor, J., \& Bever, T. G. (1965). The psychological reality of linguistic segments. Journal of Verbal Learning and Verbal Behavior, 4, 414-420.

Forster, K., \& Chambers, S. (1973). Lexical access and naming time. Journal of Verbal Learning and Verbal Behavior, 12, 627-635.

Freeman, D., \& Bentall, R. P. (2017). The concomitants of conspiracy concerns. Social Psychiatry and Psychiatric Epidemiology, 52, 595-604. https://doi.org/10.1007/ s00127-017-1354-4.

Freire, P. (1984). Pedagogy of the oppressed. New York: Continuum.

Freire, P., \& Macedo, D. (1987). Literacy: reading the word and the world. Massachusetts: Bergin \& Garvey Publishers.

Freud, S. (1916). Jokes and their relation to the unconscious. Harmondsworth, UK: Penguin.

Fuhrman, O., \& Boroditsky, L. (2010). Cross-cultural differences in mental representations of time: Evidence from an implicit non-linguistic task. Cognitive Science, 34, 1430-1451. https://doi.org/10.1111/j.1551-6709.2010. 01105.x.

Gagliano, M. (2017). The mind of plants. Think the unthinkable. Communicative and Integrative Biology, 10, e1288333. https://doi.org/10.1080/19420889.2017.1288333.

Gayton, A., \& Newman, S. (1940). Yokuts and Western Mono Myths. Berkeley: University of California Anthropological Records 5. (new edition: Kraus Reprint Co., 1976).

Gazzaniga, M. S. (1985). The Social Brain: Discovering the Networks of the Mind. New York: Basic Books.

Gazzaniga, M. S. (1989). Organization of the human brain. Science New Series, 245(4921), 947-956.

Gelerstein, D., Del Rio, R., Nussbaum, M., Chiuminatto, P., \& López, X. (2016). Designing and implementing a test for measuring critical thinking in primary school. Thinking Skills and Creativity, 20, 40-49. https://doi.org/10.1016/j. tsc.2016.02.002.

Gilbert, D. T. (1991). How mental systems believe. American Psychologist, 46, 107-119.

Gilbert, D. T., Krull, D. S., \& Malone, P. S. (1990). Unbelieving the unbelievable: some problems in the rejection of false information. Journal of Personality and Social Psychology, 59, 601-613.

Golding, M. P. (1986). A note on discovery and justification in science and law. Nomos, 28, 124-140.

Goody, J. (1977). The domestication of the savage mind. New York: Cambridge University Press.

Goody, J., \& Watt, I. (1963). The consequences of literacy. Comparative Studies in Society and History, 5, 304-345.

Gould, S. J. (1981). The Mismeasure of Man. New York, NY: Norton.

Gould, S. J. (1982). A nation of morons. New Scientist, 6, 349-352. (This paper is an edited extract from The Mismeasure of Man).
Gresson, A., Kincheloe, J., \& Steinberg, S. R. (1997). Measured lies: the bell curve examined. New York: St. Martin's Press.

Griffin, D. (1976). The question of animal awareness: evolutionary continuity of mental experience. New York: Rockefeller University Press.

Harris, R. (2000). Rethinking Writing. London: Athlone Press.

Harris, R. (2009). Rationality and the literate mind. London: Routledge.

Harris, W. (1989). Ancient literacy. Cambridge, MA: Harvard University Press.

Hearne, V. (1994). Animal happiness. New York: Harper Collins.

Hebb, D. O. (1946). Emotion in man and animal: an analysis of the intuitive processes of recognition. Psychological Review, 53, 88-106. https://doi.org/10.1037/h0063033.

Herrnstein, R. J., \& Murray, C. (2010). The bell curve: Intelligence and class structure in American life. New York: Simon and Schuster.

Herzing, D., \& Johnson, C. (Eds.). (2015). Dolphin communication and cognition: past, present, and future. Cambridge, MA: MIT Press.

Hoskyn, M., \& Swanson, H. L. (2003). The relationship between working memory and writing in younger and older adults. Reading and Writing, 16, 759-784.

Hoyt, H. (1916). The relation of the literacy test to a constructive immigration problem. Journal of Political Economy, 24, 445-473.

Huettig, F., \& Mishra, R. K. (2014). How literacy acquisition affects the illiterate mind-A critical examination of theories and evidence. Language and Linguistics Compass, 8(10), 401-427. https://doi.org/10.1111/lnc3.12092.

Huettig, F., \& Pickering, M. J. (2019). Literacy advantages beyond reading: Prediction of spoken language. Trends in Cognitive Science, 23, 464-475. https://doi.org/10.1016/j. tics.2019.03.008.

Isberner, M.-B., \& Richter, T. (2013). Can readers ignore implausibility? Evidence for nonstrategic monitoring of. event-based plausibility in language comprehension. Acta Psychologica, 142, 15-22. https://doi.org/10.1016/j. actpsy.2012.10.003.

Isberner, M. B., \& Richter, T. (2014). Does validation during language comprehension depend on an evaluative mindset? Discourse Processes, 51, 7-25. https://doi.org/10. 1080/0163853X.2013.855867.

Israel, J. I. (2001). Radical enlightenment. Oxford: Oxford University Press.

Janks, H. (2002). Critical literacy: beyond reason. The Australian Educational Researcher, 29, 7-26. https://doi.org/ 10.1007/BF03219767.

Janks, H. (2010). Literacy and power. NY: Routledge.

Janks, H. (2013). Critical literacy in teaching and research. Education Inquiry, 4(2), 225-242. https://doi.org/10.3402/ edui.v4i2.22071.

Jolley, D., \& Douglas, K. (2014). The social consequences of conspiracism: Exposure to conspiracy theories decreases intentions to engage in politics and to reduce one's carbon footprints. British Journal of Psychology, 105, 35-56. https://doi.org/10.1111/bjop.12018.

Kalmar, I. (1985). Are there really no primitive languages? In D. R. Olson, N. Torrance, \& A. Hildyard (Eds.), Literacy, 
language and learning (pp. 148-166). Cambridge: Cambridge University Press.

Kanazawa, S. (2006). Mind the gap...in intelligence: Re-examining the relationship between inequality and health. British Journal of Health Psychology, 11, 623-642. https:// doi.org/10.1348/135910705X69842.

Karanth, P., Kudva, A., \& Mjayan, A. (1995). Literacy and linguistic awareness. In B. de Gelder \& J. Morais (Eds.), Speech and reading: A comparative approach (pp. 303-316). London: Erlbaum.

Karpova, S. (1966). The preschooler's realisation of the lexical structure of speech. Synopsis. In D. Slobin, F. Smith, \& G. Miller (Eds.), The Genesis of Language: A psycholinguistic approach. Cambridge MA: MIT Press.

Kellogg, R. T. (1994). The psychology of writing. New York: Oxford University Press.

Kennedy, E. (1979). "Ideology" from Destutt De Tracy to Marx. Journal of the History of Ideas, 40, 353-368.

Kievit, R. A., Hofman, A. D., \& Nation, K. (2019). Mutualistic coupling between vocabulary and reasoning in young children: A replication and extension of the study by Kievit et al. (2017). Psychological Science, 30, 1245-1252. https://doi.org/10.1177/0956797619841265.

Kievit, R. A., Lindenberger, U., Goodyer, I. M., Jones, P. B., Fonagy, P., Bullmore, E. T., The Neuroscience in Psychiatry Network, \& Dolan, R.J. (2017). Mutualistic coupling between vocabulary and reasoning supports cognitive development during late adolescence and early adulthood. Psychological Science, 28, 1419-1431. https://doi.org/10. 1177/0956797617710785.

Kolinsky, R. (2015). How learning to read influences language and cognition. In A. Pollatsek \& R. Treiman (Eds.), The Oxford Handbook of Reading. New York, NY: Oxford University Press (pp. 377-393). https://doi.org/10.1093/ oxfordhb/9780199324576.013.29.

Kolinsky, R., Cary, L., \& Morais, J. (1987). Awareness of words as phonological entities: the role of literacy. Applied Psycholinguistics, 8, 223-232.

Kolinsky, R., Monteiro-Plantin, R. S., Mengarda, E. J., GrimmCabral, L., Scliar-Cabral, L., \& Morais, J. (2014). How formal education and literacy impact on the content and structure of semantic categories. Trends in Neuroscience and Education, 3, 106-121. https://doi.org/10.1016/j.tine. 2014.08.001.

Kolinsky, R., \& Morais, J. (2018). The worries of wearing literate glasses. L'Année Psychologique/Topics in Cognitive Psychology, 118, 321-347. https://doi.org/10.3917/ anpsy1.184.0321.

Kolinsky, R., Pattamadilok, C., \& Morais, J. (2012). The impact of orthographic knowledge on speech processing. Ilha do Desterro, 63, 161-186.

Kolinsky, R., Verhaeghe, A., Fernandes, T., Mengarda, E. J., Grimm-Cabral, L., \& Morais, J. (2011). Enantiomorphy through the looking-glass: Literacy effects on mirror-image discrimination. Journal of Experimental Psychology: General, 140, 210-238. https://doi.org/10.1037/a0022168.

Koopmans, M. (1987). Formal schooling and task familiarity: a reply to Morais et al. Cognition, 27, 109-111.

Kosmidis, M. H., Zafiri, M., \& Politimou, N. (2011). Literacy versus formal schooling: influence on working memory.
Archives of Clinical Neuropsychology, 26, 575-582. https://doi.org/10.1093/arclin/acr063.

Kovas, Y., Voronin, I., Kaydalov, A., Malykh, S. B., Dale, P. S., \& Plomin, R. (2013). Literacy and numeracy are more heritable than intelligence in primary school. Psychological Science, 24, 2048-2056. https://doi.org/10.1177/ 0956797613486982.

Kurvers, J., Van Hout, R. \& Vallen, T. (2007). Literacy and word boundaries. In N. Faux (Ed.) Low-educated second language and literacy acquisition: Research, policy and practice: Proceedings of the second annual forum (pp. 45-64). Richmond, Virginia: The Literacy Institute at Virginia Commonwealth University.

Lankshear, C., \& McClaren, P. (Eds.). (1993). Critical literacy: radical and postmodernist perspectives. Albany: SUNY Press.

Lashley, K. S. (1959). Persistent problems in the evolution of mind. Quarterly Journal of Biology, 24, 28-42.

Lee, C. J. (2011). Myths about critical literacy: What teachers need to unlearn. Journal of Language and Literacy Education, 7, 95-102.

Leiper, K. (2013). Education, literacy and its cognitive effects: problem-solving and decision-making in Homer and archaic and fifth century BC Athens. Ph.D. dissertation, Department of Ancient History, Macquarie University.

Liu, F., \& Stapleton, P. (2014). Counterargumentation and the cultivation of critical thinking in argumentative writing: Investigating washback from a high-stakes test. System, 45, 117-128. https://doi.org/10.1016/j.system.2014.05.005.

Luria, A. R. (1976). Cognitive development. Its cultural and social foundations. Cambridge: Harvard University Press.

Lynn, B. C. (2006). End of the line: The rise and coming fall of the global corporation. New York: Broadway Business.

Lynn, R., \& Vanhanen, T. (2002). IQ and the wealth of nations. Westport, CT: Praeger.

Malcom, N. (1977). Thought and Knowledge. Ithaca, New York: Cornell.

Mancosu, M., Vassallo, S., \& Vezzoni, C. (2017). Believing in conspiracy theories: evidence from an exploratory analysis of Italian survey data. South European Society and Politics, 22, 327-344. https://doi.org/10.1080/13608746.2017. 1359894.

Mandelbaum, E. (2014). Thinking is believing. Inquiry, 57, 55-96. https://doi.org/10.1080/0020174X.2014.858417.

Marino, L., \& Colvin, C. M. (2015). Thinking pigs: A comparative review of cognition, emotion, and personality in Sus domesticus. International Journal of Comparative Psychology, 28, 1-22.

Matthews, G. B. (1978). Animals and the unity of psychology. Philosophy, 53, 437-454.

Mocan, N. H., \& Pogorelova, L. (2017). Compulsory schooling laws and formation of beliefs: education, religion and superstition. Journal of Economic Behavior and Organization, 142, 509-539. https://doi.org/10.1016/j.jebo.2017. 07.005 .

McCutchen, D. (2011). From novice to expert: Implications of language skills and writing-relevant knowledge for memory during the development of writing skill. Journal of Writing Research, 3, 51-68. https://doi.org/10.17239/jowr2011.03.01.3. 
McCutchen, D., Covill, A., Hoyne, S. H., \& Mildes, K. (1994). Individual differences in writing: implications of translating fluency. Journal of Educational Psychology, 86, 256.

Mercier, H., Bernard, S., \& Clément, F. (2014). Early sensitivity to arguments: How preschoolers weight circular arguments. Journal of Experimental Child Psychology, 125, 102-109. https://doi.org/10.1016/j.jecp.2013.11.011.

Mercier, H., \& Sperber, D. (2011). Why do humans reason? Arguments for an argumentative theory. Behavioral and Brain Sciences, 34, 57-74. https://doi.org/10.1017/ S0140525X10000968f.

Mercier, H., \& Sperber, D. (2017). The enigma of reason. Cambridge: Harvard University Press.

Milne, D. (2005). Teaching the brain to read. Ottawa: SK Publishing.

Mishra, R. K., Singh, N., Pandey, A., \& Huettig, F. (2012). Spoken language-mediated anticipatory eye-movements are modulated by reading ability-evidence from Indian low and high literates. Journal of Eye Movement Research, 5, 1-10. https://doi.org/10.16910/jemr.5.1.3.

Missiou, A. (2011). Literacy and democracy in fifth-century Athens. Cambridge: Cambridge University Press.

Morais, J. (2018). Literacy and democracy. Language, Cognition and Neuroscience, 33, 351-372. https://doi.org/10. 1080/23273798.2017.1305116.

Morais, J., Bertelson, P., Cary, L., \& Alegria, J. (1986). Literacy training and speech segmentation. Cognition, 24, 45-64.

Morais, J., Cary, L., Alegria, J., \& Bertelson, P. (1979). Does awareness of speech as a sequence of phones arise spontaneously? Cognition, 7, 323-331.

Morais, J., Castro, S. L., Scliar-Cabral, L., Kolinsky, R., \& Content, A. (1987). The effects of literacy on the recognition of dichotic words. Quarterly Journal of Experimental Psychology, 39A, 451-465.

Murdoch, K. (1920). A study of race differences in New York City. School and Society, 11, 147-150.

Myers, D. G. (2019). Psychological Science meets a gullible post-truth world. In P. Forgas \& R. F. Baumeister (Eds.), The social psychology of gullibility. Fake news conspiracy theories, and irrational beliefs (pp. 77-100). London: Psychological Press.

Nadarevic, L., \& Erdfelder, E. (2019). More evidence against the Spinozan model: Cognitive load diminishes memory for "true" feedback. Memory \& Cognition, 47, 1386-1400. https://doi.org/10.3758/s13421-019-00940-6.

OECD. (2016), Skills Matter: Further results from the survey of adult skills. Paris: OECD Skills Studies, OECD Publishing. https://doi.org/10.1787/9789264258051-en

OECD. (2019). PISA 2018 Results (Volume I): What students know and can do. Paris: PISA, OECD Publishing. https:// doi.org/10.1787/5f07c754-en.

Oldfather, Ch. M. (2008). Writing, cognition, and the nature of the judicial functions. Georgetown Law Journal, 96, 1283-1345.

Oliver, J. E., \& Wood, T. (2014). Medical conspiracy theories and health behaviors in the United States. JAMA Internal Medicine, 174, 817-818. https://doi.org/10.1001/ jamainternmed.2014.190.

Ong, W. J. (1982). Orality and literacy: The technologizing of the word. New York, NY: Methuen.
Osvath, M., \& Martin-Ordas, G. (2014). The future of futureoriented cognition in non-humans: theory and the empirical case of the great apes. Philosophical Transactions of the Royal Society B, 369(1655), 20130486. https://doi.org/10. 1098/rstb.2013.0486.

Ouellet, M., Santiago, J., Israeli, Z., \& Gabay, S. (2010). Is the future the right time? Experimental Psychology, 57, 308-314. https://doi.org/10.1027/1618-3169/a000036.

Padakannaya, P., Devi, M. L., Zaveria, B., Chengappa, S. K., \& Vaid, J. (2002). Directional scanning effect and strength of reading habit in picture naming and recall. Brain and Cognition, 48, 484-490.

Pantazi, M., Kissine, M., \& Klein, O. (2018). The power of truth bias: False Information affects memory and judgment even in the absence of distraction. Social Cognition, 36, 167-198. https://doi.org/10.1521/soco.2018.36.3.381.

Pattamadilok, C., Lafontaine, H., Morais, J., \& Kolinsky, R. (2010). Auditory word serial recall benefits from orthographic dissimilarity. Language and Speech, 53, 321-341. https://doi.org/10.1177/0023830910371450.

Pattamadilok, C., Morais, J., Colin, C., \& Kolinsky, R. (2014). Unattentive speech processing is influenced by orthographic knowledge: Evidence from mismatch negativity. Brain and Language, 137, 103-111. https://doi.org/10. 1016/j.bandl.2014.08.005.

Pattamadilok, C., Perre, L., Dufau, S., \& Ziegler, J. C. (2009). On-line orthographic influences on spoken language in a semantic task. Journal of Cognitive Neuroscience, 21, 169-179. https://doi.org/10.1162/jocn.2009.21014.

Peereman, R., Dufour, S., \& Burt, J. S. (2009). Orthographic influences in spoken word recognition: the consistency effect in semantic and gender categorization tasks. Psychonomic Bulletin \& Review, 16, 363-368. https://doi.org/ 10.3758/PBR.16.2.363.

Pegado, F., Comerlato, E., Ventura, F., Jobert, A., Nakamura, K., Buiatti, M., et al. (2014). Timing the impact of literacy on visual processing. Proceedings of the National Academy of Sciences of the United States of America, 111(49), E5233-E5242. https://doi.org/10.1073/pnas.1417347111.

Pelandré, N. L. (1998). Efeitos a longo prazo do método de alfabetização de Paulo Freire. [Long-term effects of Paulo Freire's literacy method]. Unpublised, Ph.D., Universidade Federal de Santa Catarina, Florianópolis, Brazil.

Pelandré (2002). Ensinar e aprender com Paulo Freire-40 horas e 40 anos depois. [Teaching and learning with Paulo Freire-40 hours and 40 years later]. São Paulo: Corte/ Instituto Paulo Freire Freirean.

Pepperberg, I. (1995). Grey parrot intelligence. In Proceedings of the International Aviculturists Society (pp. 358-382). Chicago: University of Chicago Press.

Piest, B., Isberner, M.-B., \& Richter, T. (2018). Don't believe everything you hear: routine validation of audiovisual information in children and adults. Memory \& Cognition, 46, 849-863. https://doi.org/10.3758/s13421-018-0807-7.

Ramachandra, V., \& Karanth, P. (2007). The role of literacy in the conceptualization of words: data from Kannadaspeaking children and non-literate adults. Reading and Writing, 20, 173-199.

Ransdell, S., \& Levy, C. M. (1996). Working memory constraints on writing quality and fluency. In C. M. Levy \& S. Ransdell (Eds.), The science of writing: Theories, methods, 
individual differences, and applications (pp. 93-105). New York: Lawrence Erlbaum Associates.

Reis, A., Guerreiro, M., \& Petersson, K. M. (2003). A sociodemographic and neuropsychological characterization of anilliterate population. Applied Neuropsychology, 10, 191-204.

Richwine, J. (2009). IQ and immigration policy. Doctoral dissertation. Harvard University.

Rinaldi, L., I Di Luca, S., Henik, A., \& Girelli, L. (2014). Reading direction shifts visuospatial attention: An interactive account of attentional biases. Acta Psychologica, 151,98-105. https://doi.org/10.1016/j.actpsy.2014.05.018.

Rindermann, H., Woodley, M. A., \& Stratford, J. (2012a). Haplogroups as evolutionary markers of cognitive ability. Intelligence, 40, 362-375. https://doi.org/10.1016/j.intell. 2012.04.002.

Rindermann, H. (2012b). Intellectual classes, technological progress and economic development: the rise of cognitive capitalism. Personality and Individual Differences, 53(2), 108-113. https://doi.org/10.1016/j.paid.2011.07.001.

Román, A., El Fathi, A., \& Santiago, J. (2013). Spatial biases in understanding descriptions of static scenes: the role of reading and writing direction. Memory \& Cognition, 41, 588-599. https://doi.org/10.3758/s13421-012-0285-2.

Rosenthal, J., \& Ehri, L. C. (2011). Pronouncing new words aloud during the silent reading of text enhances fifth graders' memory for vocabulary words and their spellings. Reading and Writing, 24, 921-950.

Scholes, R. J. (1993). On the orthographic basis of morphology. In R. J. Scholes (Ed.), Literacy and language analysis (pp. 73-95). Hillsdale, NJ: Lawrence Erlbaum.

Scholes, R. J., \& Willis, B. J. (1987a). a). Language and literacy. Journal of Literary Semantics, 16, 3-11.

Scholes, R. J., \& Willis, B. J. (1987b). b). Age and education in oral language skills. Developmental Neuropsychology, 3, 239-248.

Scribner, S., \& Cole, M. (1981). The psychology of literacy. Cambridge: Harvard University Press.

Schwanenflugel, P. J., Meisinger, E. B., Wisenbaker, J. M., Kuhn, M. R., Strauss, G. B., \& Morris, R. D. (2006). Becoming a fluent and automatic reader in the early elementary school years. Reading Research Quarterly, 41, 496-522. https://doi.org/10.1598/RRQ.41.4.4.

Share, D. L. (1995). Phonological recoding and self-teaching: Sine qua non of reading acquisition. Cognition, 55, 151-218.

Share, D. L. (1999). Phonological recoding and orthographic learning: a direct test of the self-teachinghypothesis. Journal of Experimental Child Psychology, 72, 95-129.

Silva, H., \& Prado, I. G. O. (2010). Creationism and intelligent design: presence in the Brazil educational policy. Procedia Social and Behavioural Sciences, 2, 5260-5264. https:// doi.org/10.1016/j.sbspro.2010.03.856.

Sperber, D. (2001). An evolutionary perspective on testimony and argumentation. Philosophical Topics, 29, 401-413.

Stanovich, K. E. (1980). Toward an interactive-compensatory model of individual differences in the development of reading fluency. Reading Research Quarterly, 16, 32-71.

Stanovich, K. E. (2013). Why humans are (sometimes) less rational than other animals: cognitive complexity and the axioms of rational choice. Thinking \& Reasoning, 19, 1-26. https://doi.org/10.1080/13546783.2012.713178.

Steward, H. (2009). Animal agency. Inquiry, 52, 217-231. https://doi.org/10.1080/00201740902917119.

Street, J. A., \& Dabrowska, E. (2010). More individual differences in language attainment: How much do adult native speakers of English know about passives and quantifiers? Lingua, 120, 2080-2094. https://doi.org/10.1016/j.lingua. 2010.01.004.

Sugiyama, M. S. (2017). Oral storytelling as evidence of pedagogy in forager societies. Frontiers in Psychology, 8(471), 1-11. https://doi.org/10.3389/fpsyg.2017.00471.

Sugiyama, M. S. (2011). The forager oral tradition and the evolution of prolonged juvenility. Frontiers in Psychology, 2, 133. https://doi.org/10.3389/fpsyg.2011.00133.

Swami, V., Stieger, S., Pietschnig, J., Nader, I. W., \& Voracek, M. (2012). Using more than $10 \%$ of our brains: examining belief in science-related myths from an individual differences perspective. Learning and Individual Differences, 22, 404-408. https://doi.org/10.1016/j.lindif.2011.12.005.

Sweeney, A. (1922). Mental tests for immigrants. The North American Review, 215(798), 600.

Taylor, A. H. (2014). Corvid cognition. WIREs. Cognitive Science, 5, 61-372. https://doi.org/10.1002/wcs.1286.

Thomas, R. (1992). Literacy and Orality in Ancient Greece. Cambridge: Cambridge University Press.

Thomas, R. (2009). Writing, reading, public and private "Literacies" (pp. 13-45). Ancient literacies: The culture of reading in Greece and Rome.

Tomasello, M. (2014). A natural history of human thinking. Cambridge: Harvard University Press.

Tucker, W. H. (1994). The Science and Politics of Racial Research. Urbana: University of Illinois Press.

Tucker, W. H. (2002). The Funding of Scientific Racism: Wickliffe Draper and the Pioneer Fund. Urbana: University of Illinois Press.

Uscinski, J. E., \& Parent, J. M. (2014). American conspiracy theories. New York: Oxford University Press.

UNESCO (1997). International standard classification of education. Paris: ISCED. https://unesdoc.unesco.org/images/ 0023/002322/232205e.pdf.

Van Prooijen, J.-W. (2017). Why education predicts decreased belief in conspiracy theories. Applied Cognitive Psychology, 31, 50-58. https://doi.org/10.1002/acp.3301.

Van Prooijen, J.-W., Krouwel, A. P. M., \& Pollet, T. (2015). Political extremism predicts belief in conspiracy theories. Social Psychological and Personality Science, 6, 570-578. https://doi.org/10.1177/1948550614567356.

Ventura, P., Fernandes, T., Cohen, L., Morais, J., Kolinsky, R., \& Dehaene, S. (2013). Literacy acquisition reduces the automatic holistic processing of faces and houses. Neuroscience Letters, 554, 105-109.

Ventura, P., Morais, J., Pattamadilok, C., \& Kolinsky, R. (2004). The locus of the orthographic consistency effect in auditory word recognition. Language and Cognitive Processes, 19, 57-95. https://doi.org/10.1080/01690960601049628.

Verhaeghe, A., \& Kolinsky, R. (2006). O que os iletrados nos ensinam sobre os testes de inteligência. [What illiterates teach us about intelligence tests]. Lisbon: Fundação Calouste Gulbenkian- Fundação para a Ciência e a Tecnologia. 
Wardle, C. \& Derakhshan, H. (2017). Information disorder: Toward an interdisciplinary framework for research and policy making. Council of Europe report DGI(2017)09. Strasbourg: Council of Europe.

Wason, P. (1966). Reasoning. In B. M. Foss (Ed.), New horizons in psychology. Harmondsworth: Penguin.

Wasserstrom, R. A. (1961). The judicial decision: toward a theory of legal justification. Palo Alto: Stanford University Press.

Weil, R., \& Mudrik, L. (2020). Detecting falsehood relies on mismatch detection between sentence components. Cognition, 195, 104-121. https://doi.org/10.1016/j.cognition. 2019.104121.

Weil, R., Schul, Y., \& Mayo, R. (2020). Correction of evident falsehood requires explicit negation. Journal of Experimental Psychology: General., 149, 290-310. https://doi. org/10.1037/xge0000635.

West, R. F., \& Stanovich, K. E. (1982). Source of inhibition in experiments on the effect of sentence context on word recognition. Journal of Experimental Psychology: Learning, Memory, \& Cognition, 8, 385-399.
Wilde, L. (2000). "The creatures, too, must become free": Marx and the animal/human distinction. Capital and Class, 24, 37-53. https://doi.org/10.1177/030981680007200103.

Young, K. (1922). Intelligence tests of certain immigrant groups. The Scientific Monthly, 15, 417-434.

Ziegler, J. C., \& Ferrand, L. (1998). Orthography shapes the perception of speech: the consistency effect in auditory recognition. Psychonomic Bulletin \& Review, 5, 683-689.

Ziegler, J. C., Petrova, A., \& Ferrand, L. (2008). Feedback consistency effects in visual and auditory word recognition: where do we stand after more than a decade? Journal of Experimental Psychology: Learning, Memory, and Cognition, 34, 643-661. https://doi.org/10.1037/02787393.34.3.643.

Zuboff, S. (2019). The age of surveillance capitalism. The fight for a human future at the new frontier of power. London: Profile Books.

Publisher's Note Springer Nature remains neutral with regard to jurisdictional claims in published maps and institutional affiliations. 